\title{
Protection of the heart by treatment with a divalent-copper-selective chelator reveals a novel mechanism underlying cardiomyopathy in diabetic rats
}

Lin Zhang ${ }^{1,2}$, Marie-Louise Ward ${ }^{2+}$, Anthony RJ Phillips ${ }^{1,3}$, Shaoping Zhang ${ }^{1}$, John Kennedy ${ }^{4}$, Bernard Barry ${ }^{4}$, Mark B Cannell ${ }^{2,7}$ and Garth JS Cooper ${ }^{1,5,6^{*}+}$

\begin{abstract}
Background: Intracellular calcium $\left(\mathrm{Ca}^{2+}\right)$ coordinates the cardiac contraction cycle and is dysregulated in diabetic cardiomyopathy. Treatment with triethylenetetramine (TETA), a divalent-copper-selective chelator, improves cardiac structure and function in patients and rats with diabetic cardiomyopathy, but the molecular basis of this action is uncertain. Here, we used TETA to probe potential linkages between left-ventricular (LV) copper and $\mathrm{Ca}^{2+}$ homeostasis, and cardiac function and structure in diabetic cardiomyopathy.

Methods: We treated streptozotocin-diabetic rats with a TETA-dosage known to ameliorate LV hypertrophy in patients with diabetic cardiomyopathy. Drug treatment was begun either one (preventative protocol) or eight (restorative protocol) weeks after diabetes induction and continued thereafter for seven or eight weeks, respectively. Total copper content of the LV wall was determined, and simultaneous measurements of intracellular calcium concentrations and isometric contraction were made in LV trabeculae isolated from control, diabetic and TETA-treated diabetic rats.

Results: Total myocardial copper levels became deficient in untreated diabetes but were normalized by TETA-treatment. Cardiac contractility was markedly depressed by diabetes but TETA prevented this effect. Neither diabetes nor TETA exerted significant effects on peak or resting $\left[\mathrm{Ca}^{2+}\right]_{\mathrm{j}}$. However, diabetic rats showed extensive cardiac remodelling and decreased myofibrillar calcium sensitivity, consistent with observed increases in phosphorylation of troponin I, whereas these changes were all prevented by TETA.

Conclusions: Diabetes causes cardiomyopathy through a copper-mediated mechanism that incorporates myocardial copper deficiency, whereas TETA treatment prevents this response and maintains the integrity of cardiac structure and myofibrillar calcium sensitivity. Altered calcium homeostasis may not be the primary defect in diabetic cardiomyopathy. Rather, a newly-described copper-mediated mechanism may cause this disease.
\end{abstract}

Keywords: Copper homeostasis, Calcium homeostasis, Anti-oxidant defence, Cardiac contraction, Cardiovascular disease, Copper deficiency, Copper excess, Cardiomyopathy, Diabetes mellitus, Essential trace nutrient, Experimental therapeutics, Left-ventricular dysfunction, Left-ventricular remodelling, Calcium responsiveness, Myocardium, Myocardial calcium sensitivity, QT interval, Triethylenetetramine, Troponin

\footnotetext{
* Correspondence: g.cooper@auckland.ac.nz

${ }^{\dagger}$ Equal contributors

'School of Biological Sciences, Faculty of Science, University of Auckland, Private Bag 92019, Auckland 1142, New Zealand

${ }^{5}$ Centre for Advanced Discovery and Experimental Therapeutics, Manchester Biomedical Research Centre, University of Manchester, Manchester, UK Full list of author information is available at the end of the article
} 


\section{Background}

Cardiovascular disease (CVD) is the main cause of mortality in diabetic patients, in whom it is frequently accompanied by heart failure [1]. About three-quarters of the CVD risk in diabetes may be attributable to hypertension [2]. Other significant contributors to risk include obesity, atherosclerosis, dyslipidaemia, endothelial dysfunction, defective platelet function, coagulation abnormalities, and diabetic cardiomyopathy [2]. The latter condition is considered to be a diabetes-specific cardiomyopathy, which is independent of macrovascular and microvascular disease and which contributes substantively to morbidity and mortality [2-4].

Effective treatments for established heart failure in diabetes are limited $[4,5]$ and its prognosis is particularly poor in patients with type-2 diabetes (T2D) [6]. Elevated risk persists despite best available treatments with existing classes of medications, so new and improved therapeutic approaches for heart failure in diabetes are required.

Copper is an essential trace element that plays key roles in many vital copper enzymes, e.g. cytochrome c oxidase, caeruloplasmin, copper/zinc superoxide dismutase (SOD1), and lysyl oxidase [7]. Free divalent copper, $\mathrm{Cu}(\mathrm{II})$, is the most redox-active metal ion in mammalian tissues and excess can cause tissue damage by generating highly-reactive hydroxyl radicals [8], which inactivate essential enzymes and cause lipid peroxidation and DNA damage, thereby disrupting cell metabolism $[9,10]$.

Insufficient dietary copper intake can cause systemic copper deficiency, myocardial copper deficiency, hypertrophic cardiomyopathy, and heart failure [11-14], all of which are reversible by restoration of normal copper intake [15]. Moreover, there is evidence that dietary copper supplementation reversed hypertrophic cardiomyopathy induced by chronic pressure overload in mice consuming a normal-copper diet; in that study, LV copper levels fell by $\sim 20 \%$ as a result of the pressure overload [16], but systemic copper balance was not reported.

Copper accumulation in excess of bodily requirements is also cytotoxic $[17,18]$. Altered tissue copper levels have sometimes been reported to accompany diabetes in patients or animal models $[19,20]$. We have shown, however, in a phase- 2 trial that employed a balance study, that T2D patients acquire substantive copper overload, and that they do not demonstrate systemic signs of copper deficiency. Copper regulation in diabetic patients is thus clearly differentiated from the copper deficiency states that occur in animals and, rarely, in patients [21,22]. The significance of dysregulated copper in diabetes-evoked heart disease was substantively strengthened when we showed that the $\mathrm{Cu}(\mathrm{II})$-selective chelator, TETA can restore cardiac structure and function in diabetic patients and animals, without concomitant lowering of blood glucose or systemic blood pressure [23,24].
T2D patients acquire a hyperglycaemia-driven pathogenic abnormality of copper homeostasis that is reversible by TETA-treatment [25], which also restores LV mass in patients with LV hypertrophy (LVH) [24]. TETA is a highly-selective divalent copper chelator [25,26], which is used as a second-line treatment for Wilson's disease [27]. In rats used as a model of diabetic cardiomyopathy, TETA causes cardiac regeneration [23], reversal of LV dysfunction [28], and improved antioxidant defences [23,29]. In aggregate, these findings provide substantive support for the idea that defective copper regulation plays a key role in the pathogenesis of cardiomyopathy and LV dysfunction in diabetes [22]. However, the molecular basis for this linkage remains uncertain, and motivated the current study. The evidence linking defective copper regulation to the pathogenesis of the diabetic complications in the heart, kidneys, arteries and nerves has recently been reviewed $[21,22]$.

Defects in intracellular $\mathrm{Ca}^{2+}$ homeostasis have been implicated in the impaired mechanical performance of the diabetic heart $[4,30-32]$ but there is no current consensus from published studies, where resting $\mathrm{Ca}^{2+}$ has been reportedly decreased [33-35], increased [36,37], or unchanged $[38,39]$. Similarly, the amplitude of the $\mathrm{Ca}^{2+}$ transient has also been reported as decreased [35,40-42], increased [36], or unchanged [43,44]. Therefore, we reexamined the changes in $\mathrm{Ca}^{2+}$ homeostasis underlying diabetic cardiomyopathy in the current study. We also determined whether TETA exerts its inotropic effects by modifying intracellular $\mathrm{Ca}^{2+}$ homeostasis, since copper dysregulation can generate reactive oxidative species and cause defects in anti-oxidant defences which could further accentuate abnormalities in intracellular $\mathrm{Ca}^{2+}$ regulation $[45,46]$.

Here we have tested the hypothesis in rats used as a model of the diabetic complications that diabetes might cause linked abnormalities of copper and calcium homeostasis, which could interact to yield cardiomyopathy and LV dysfunction.

\section{Methods}

Animals This study was approved by the University of Auckland Animal Ethics Committee and performed according to the Guide for the Care and Use of Laboratory Animals [47] and the ARRIVE guidelines for the reporting of animal research [48].

Reagents All chemical reagents were obtained from Sigma and were of analytical grade or better, unless otherwise stated.

Induction and verification of diabetes in rats Diabetes was induced in adult male Wistar rats (200-250 g bodywt; 6-7 weeks of age) by a single intravenous injection of STZ (60 mg/kg body-wt dissolved in $0.9 \%$ saline) as described [32]; control rats received $0.9 \%$ saline only. 
Diabetes was diagnosed by demonstration of sequential tail-vein blood glucose concentrations $>11 \mathrm{mmol} / \mathrm{L}$ [23]. TETA disuccinate (CarboGen, Switzerland; $30 \mathrm{mg} /$ day-rat) in the drinking water (18 M 2 ; MilliQ, Millipore, Billerica, MA) [49] was begun either one week after injection and continued for a further 7 weeks (preventative protocol, [32]), or 8 weeks after injection and continued for a further 8 weeks (restorative protocol [23]). Throughout the study, animals were housed (in pairs) in a temperature-controlled unit with a fixed 12-hr light/dark cycle, and received ad libitum access to food and water.

Rationale for choice of drug dosage We based the choice of TETA dosage used here on those employed in known clinical applications of TETA (TETA dihydrochloride or trientine) in the treatment of Wilson's disease, and for the experimental therapy of diabetes. Dosages employed for the treatment of Wilson's disease in adults typically vary from 750-2000 mg/day (equivalent to $10.7-28.6 \mathrm{mg} / \mathrm{kg}$-day in 70-kg adults) [50]. Here, we administered TETA disuccinate (a new salt form with improved stability characteristics [49]) in the drinking water to diabetic rats at $30 \mathrm{mg} /$ day (equivalent to $\sim 17 \mathrm{mg} /$ day-rat or $\sim 68 \mathrm{mg} / \mathrm{kg}$-day of trientine in 250 -g rats). This dosage is supported by our published doserising phase-1 clinical trial, where we showed that dosages of 1200 and $3600 \mathrm{mg} /$ day (equivalent to 17 and $51 \mathrm{mg} / \mathrm{kg}$-day in 70-kg adults) were effective and well tolerated in healthy human volunteers [51] and also by our published phase-2 trial where $1200 \mathrm{mg} /$ day of trientine $(\sim 17 \mathrm{mg} / \mathrm{kg}$-day in 70-kg adults) administered for 12 months markedly improved LV mass in T2D patients with LVH [24].

Measurement of myocardial copper levels was performed by applying particle-induced X-ray emission spectroscopy (PIXE) with Rutherford backscattering spectrometry (RBS) in freeze-dried sections of ex vivo LV myocardium [52] according to established methods [53]. The calibration, measurements and limits of detection were based on the areas of the $K \alpha$ x-ray peaks as assessed by the software package GUPIX Elemental, and concentrations were extracted from PIXE spectra using GUPIX software (gupix@listserv.uoguelph.ca).

Force and $\left[\mathrm{Ca}^{2+}\right]_{i}$ in left ventricular trabeculae were measured as previously described [54]. Briefly, unbranched and cylindrical trabeculae were dissected free from the underlying LV tissue and mounted on a force transducer (AE801, SensorOne, Sausalito CA) on the stage of an inverted microscopy (Nikon Diaphot 300, Japan). The trabeculae were perfused with Krebs-Henseleit $(\mathrm{KH})$ solution containing (in mmol/L): $\mathrm{NaCl}, 118 ; \mathrm{KCl}, 4.75 ; \mathrm{KH}_{2} \mathrm{PO}_{4}$, 1.18; $\mathrm{MgSO}_{4}, 1.18 ; \mathrm{NaHCO}_{3}, 24.8$; and D-glucose, 10; with BDM, 20; $\mathrm{CaCl}_{2}, 0.5$; gassed with $\mathrm{O}_{2}: \mathrm{CO}_{2} 95: 5$ [vol/vol]. Once the trabeculae were producing stable stimulusevoked twitches, they were loaded with the fluorescent $\mathrm{Ca}^{2+}$ indicator fura-2/AM $(10 \mu \mathrm{mol} / \mathrm{L}, 2$-hr; Invitrogen, Carlsbad, CA). Force and $\left[\mathrm{Ca}^{2+}\right]_{\mathrm{i}}$ were then measured simultaneously at a fixed sarcomere length (2.1-2.2 $\mu \mathrm{m})$, either at $37^{\circ} \mathrm{C}, 5-\mathrm{Hz}$, and $1.5 \mathrm{mmol} / \mathrm{L}\left[\mathrm{Ca}^{2+}\right]_{\mathrm{o}}$, or other experimental conditions. The ratio of the emitted fluorescence at the two excitation wavelengths (340/380 ratio) of fura-2 was obtained (Cairn Research, Faversham, Kent, $\mathrm{UK})$ as a measurement of $\left[\mathrm{Ca}^{2+}\right]_{\mathrm{i}}$. The force measurements were normalized by the trabecular cross-sectional area and expressed as stress $\left(\mathrm{mN} / \mathrm{mm}^{2}\right)$.

The steady-state force- $\left[\mathrm{Ca}^{2+}\right]_{\mathrm{i}}$ relationship was evaluated in $\mathrm{LV}$ trabeculae treated with $5 \mu \mathrm{mol} / \mathrm{L}$ of ryanodine, a plant alkaloid considered to block ryanodine receptor channels to generate a long-lived subconductance (half-open) state [55] and eventually to deplete the sarcoplasmic-reticular calcium stores. The drug effect reached steady state after 30-min exposure, whereupon fused tetani could be reliably elicited by rapid stimulation $(12 \mathrm{~Hz})$ for $6 \mathrm{~s}$ at a series of $\left[\mathrm{Ca}^{2+}\right]_{\mathrm{o}}$ values from $0.5 \mathrm{mmol} / \mathrm{L}$ to the concentration where the maximum force was obtained. Tetanus at different $\left[\mathrm{Ca}^{2+}\right]_{0}$ was separated by a "resting" period of $2 \mathrm{~min}$. To avoid precipitation at high $\mathrm{Ca}^{2+}$ concentrations, solutions used in these experiments were switched to a phosphate-free composition including (in $\mathrm{mmol} / \mathrm{L}$ ): $\mathrm{NaCl}, 108 ; \mathrm{KCl}, 5$; $\mathrm{MgCl}_{2}$, 1; HEPES, 5; $\mathrm{NaCH}_{2} \mathrm{COOH}, 20$; and D-glucose, 10. Calibration in terms of absolute values of $\left[\mathrm{Ca}^{2+}\right]_{i}$ and data analysis were performed following published procedures $[32,54]$.

Measurement of caffeine-induced $\mathrm{Ca}^{2+}$ transients in isolated cardiomyocytes LV cardiomyocytes were isolated by enzymatic digestion with $1 \mathrm{mg} / \mathrm{ml}$ collagenase Type-II (Worthington, NJ, USA) and $0.1 \mathrm{mg} / \mathrm{ml}$ proteinase typeXXIV (Sigma, MO, USA) as previously described [56]. The yield of the isolation was usually around $\sim 80 \%$. Cardiomyoctes were loaded with fura-2/AM $(5 \mu \mathrm{mol} / \mathrm{L}$, $10 \mathrm{~min}$; Invitrogen). Rod-shaped quiescent cardiomyocytes with sharp edges and clear striations were used in the investigation. Caffeine-induced $\mathrm{Ca}^{2+}$ transients were recorded from cardiomyocytes isolated from each group of rats, which were exposed to a series of solution changes. Firstly, cells were stimulated at $1 \mathrm{~Hz}$ in normal Tyrode's solution (in mmol/L): HEPES, 10; $\mathrm{NaCl}, 143 ; \mathrm{KCl}, 5.4 ; \mathrm{MgCl}_{2}, 0.5$; glucose, 10; taurine, 20; and $\mathrm{CaCl}_{2}, 1.5 ; \mathrm{pH} 7.4$ finally adjusted with $\mathrm{NaOH}$. Then, following 30-s perfusion with Tyrode's solution with $0 \mathrm{mmol} / \mathrm{L}\left[\mathrm{Ca}^{2+}\right]_{\mathrm{o}}$ and without stimulation, $10 \mathrm{mmol} / \mathrm{L}$ caffeine was added (to functionally eliminate $\mathrm{Ca}^{2+}$ storage in the SR), and $\mathrm{Ca}^{2+}$ transients were recorded. After the $\left[\mathrm{Ca}^{2+}\right]_{\mathrm{i}}$ had decreased to the resting level, cells were perfused with Tyrode's solution incorporating $1.5 \mathrm{mmol} / \mathrm{L}\left[\mathrm{Ca}^{2+}\right]_{\mathrm{o}}$ and stimulated at $1 \mathrm{~Hz}$ (to restore the SR $\mathrm{Ca}^{2+}$ ) followed by a further series of solution changes in the following order: $0 \mathrm{mmol} / \mathrm{L}\left[\mathrm{Ca}^{2+}\right]_{\mathrm{o}}$, $30 \mathrm{~s}$; and then $10 \mathrm{mmol} / \mathrm{L}$ caffeine with $0 \mathrm{mmol} / \mathrm{L}\left[\mathrm{Na}^{+}\right]_{\mathrm{o}}$

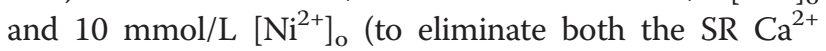


store and sarcolemmal $\mathrm{Ca}^{2+}$ extrusion via the $\mathrm{Na} / \mathrm{Ca}$ exchanger $(\mathrm{NCX}) . \mathrm{Ca}^{2+}$ transients were continuously recorded.

Western Blotting was performed with proteins extracted from LV tissue as described [32]. Briefly, frozen LV tissue was homogenized in ice-cold lysis buffer $(50 \mathrm{mmol} / \mathrm{l}$ Tris$\mathrm{HCl}, \mathrm{pH} 8 ; 150 \mathrm{mmol} / \mathrm{l} \mathrm{NaCl} ; 1 \% \mathrm{NP}-40 ; 0.5 \%$ sodium deoxycholate; and $0.1 \%$ sodium dodecylsulphate) with a proteinase inhibitor mixture and a phosphatase inhibitor mixture (Roche, Indianapolis, IN), and then centrifuged at $13,000 \mathrm{~g}$ for $1 \mathrm{~h}$ at $4^{\circ} \mathrm{C}$. Protein concentration in the supernatant was determined with a bicinchoninic acid protein assay (Pierce, Rockford, IL). Western blots were performed by using a rabbit anti-NCX antibody (Ab, 1:500, Swiss Antibodies, Swant, Switzerland), a mouse anti-SERCA2a antibody (1:1000, Affinity BioReagents, Golden, CO, USA), a mouse anti-TnT antibody (1:1000, Abcam, Cambridge, UK), and a mouse anti-TnI antibody (1:1000, Abcam). Specific signals were detected using antirabbit or anti-mouse IgG-horseradish peroxidase conjugate and ECL-Plus Western Blotting Detection Reagents (GE Healthcare, Little Chalfont, Buckinghamshire, UK) according to the manufacturer's instructions. An LAS 3000 image reader (Fuji Photo Film Co. Ltd, Tokyo, Japan) was used to detect signals and take images of the membranes. Phosphoproteins were detected by using Pro-Q Diamond phosphoprotein gel-stain followed by $\mathrm{SYPRO}^{\circ}$ Ruby total protein gel-stain (Invitrogen) and signals were detected by a Pharos FX ${ }^{\mathrm{T \mu}}$ Plus Molecular Imager (BioRad, CA). Afterwards, all images were analysed using Multi Gauge analysis software (Fuji Photo Film).

Immunohistochemistry of LV free wall was performed as described [32]. Briefly, sectioned cardiac tissues $(30 \mu \mathrm{m})$ were immunolabelled with rabbit anti-rat type-I or type-III collagen antibody (1:100 in $5 \%$ goat serum/1\% BSA/PBS; Chemicon, Boronia, Australia), and then with secondary antibody (1:200) (Alexa Fluor 488 goat anti-rabbit Ab; Invitrogen) and phalloidin-rhodamine (1:100, Invitrogen). Slides were imaged with a confocal microscope (Zeiss
LSM410). F-actin and collagen types-I and -III were quantified using a custom-written IDL analysis program based on signal-thresholding.

Statistical analysis Data are expressed as mean \pm SE. Differences between means were analysed by using analysis of variance (ANOVA) with appropriate post-hoc tests. Statistical difference was considered significant at $P<0.05$. Normality and equality of variance of samples were tested by applying the Shapiro-Wilk test or Spearman rank correlation, respectively. If either of these two tests failed, then Kruskal-Wallis one-way ANOVA with Dunn's multiple comparisons test was used for the statistical analysis. Otherwise, one-way ANOVA with the post-hoc Holm-Sidak method or Tukey's post-hoc test were used as appropriate.

\section{Results}

Metabolic responses to drug treatment TETA had no effect on the elevated blood glucose levels in diabetic rats, although it significantly increased the body-weight of diabetic rats in the latter stages of preventative treatment (Week 8; $P=0.02$, Table 1); these findings could imply the occurrence of a systemic/metabolic improvement in TETA-treated animals without improved glycaemic regulation.

TETA-treatment restored total copper content in $L V$ myocardium of diabetic rats After 16 weeks (restorative protocol as per Methods [23]), the total copper content of the LV myocardium was much lower in diabetic animals than in controls (diabetic: $29 \pm 2 \mu \mathrm{g} / \mathrm{g}$ dry LV tissue, $n=7$; control: $50 \pm 6 \mu \mathrm{g} / \mathrm{g}, n=7, P=0.030)$, whereas in TETA-treated diabetic animals, total copper was fully normalized (TETA-treated diabetic: $48 \pm 6 \mu \mathrm{g} / \mathrm{g}, n=7$, $P=0.032$ vs untreated diabetic).

TETA prevented diabetes-evoked QTc prolongation Untreated diabetes caused significant slowing of the heart rate compared with control values $(P<0.0001)$, and TETA did not modify this effect. However, QT intervals corrected for heart rate $\left(\mathrm{QT}_{\mathrm{C}}\right)$ were prolonged in diabetic rats whereas

Table 1 Descriptive variables on the experimental day (at week 8)

\begin{tabular}{|c|c|c|c|c|}
\hline & Control & Diabetic & TETA-treated diabetic & $P$ \\
\hline Body-weight (g) & $438 \pm 7(28)$ & $247 \pm 8(28)^{a}$ & $269 \pm 5(26)^{b, c}$ & $<0.0001$ \\
\hline Heart-weight (g) & $1.60 \pm 0.07(24)$ & $1.24 \pm 0.06(24)^{a}$ & $1.25 \pm 0.05(20)^{c}$ & $<0.0001$ \\
\hline Tibial length (cm) & $4.23 \pm 0.04(13)$ & $3.86 \pm 0.06(16)^{a}$ & $3.87 \pm 0.06(20)^{c}$ & $<0.0001$ \\
\hline Heart weight/Body-weight $\left(\times 10^{3}\right)$ & $3.7 \pm 0.1(23)$ & $5.3 \pm 0.2(21)^{a}$ & $5.0 \pm 0.2(20)^{c}$ & $<0.0001$ \\
\hline Heart weight/ (Tibial length) $)^{2}\left(\mathrm{mg} / \mathrm{cm}^{2}\right)$ & $94 \pm 4(13)$ & $90 \pm 5(13)$ & $84 \pm 3(20)$ & 0.23 \\
\hline Blood glucose (mmol/L) & $4.7 \pm 0.1(24)$ & $30.8 \pm 0.8(30)^{a}$ & $32.2 \pm 0.7(26)^{c}$ & $<0.0001$ \\
\hline Heart rate $\left(\mathrm{min}^{-1}\right)$ & $390 \pm 9(11)$ & $311 \pm 6(18)^{a}$ & $315 \pm 12(10)^{c}$ & $<0.0001$ \\
\hline Corrected QT interval (ms) & $177 \pm 4(11)$ & $192 \pm 4(18)^{a}$ & $138 \pm 14(10)^{b}$ & 0.001 \\
\hline
\end{tabular}

Data are means \pm SEM. Numbers of animals were as shown in parentheses. $P$-values are by Kruskal-Wallis one-way ANOVA with Dunn's multiple-comparisons test or one-way ANOVA with the Holm-Sidak method as appropriate; ${ }^{a},{ }^{b},{ }^{c}$, significant differences: ${ }^{a}$, Control vs Diabetic groups; ${ }^{b}$, Diabetic vs TETA-treated diabetic; ${ }^{c}$, Control vs TETA-treated Diabetic. 
TETA prevented the development of $\mathrm{QT}_{\mathrm{C}}$ prolongation (Table 1). By contrast, TETA treatment did not modify QTC values in non-diabetic rats (results not shown).

These data are consistent with the idea that TETAmediated prevention of QTc prolongation resulted from normalization of myocardial copper regulation, pointing to the existence of copper-mediated mechanisms that contribute to QTc regulation.
TETA prevented the diabetes-evoked deterioration of cardiac contractility Diabetic rats showed depressed peak stress compared to controls $(P=0.02$; Figures $1 \mathrm{Bii}, 2 \mathrm{Aiii})$ but this response was prevented by TETA $(P=0.04)$. Resting stress was not significantly different between experimental groups (Figures 1Bii, 2Aiv). Neither diabetic status nor TETA exerted significant effects on the levels of peak/or resting $\left[\mathrm{Ca}^{2+}\right]_{\mathrm{i}}$ (Figures $1 \mathrm{Bi}, 2 \mathrm{Ai}$, ii).

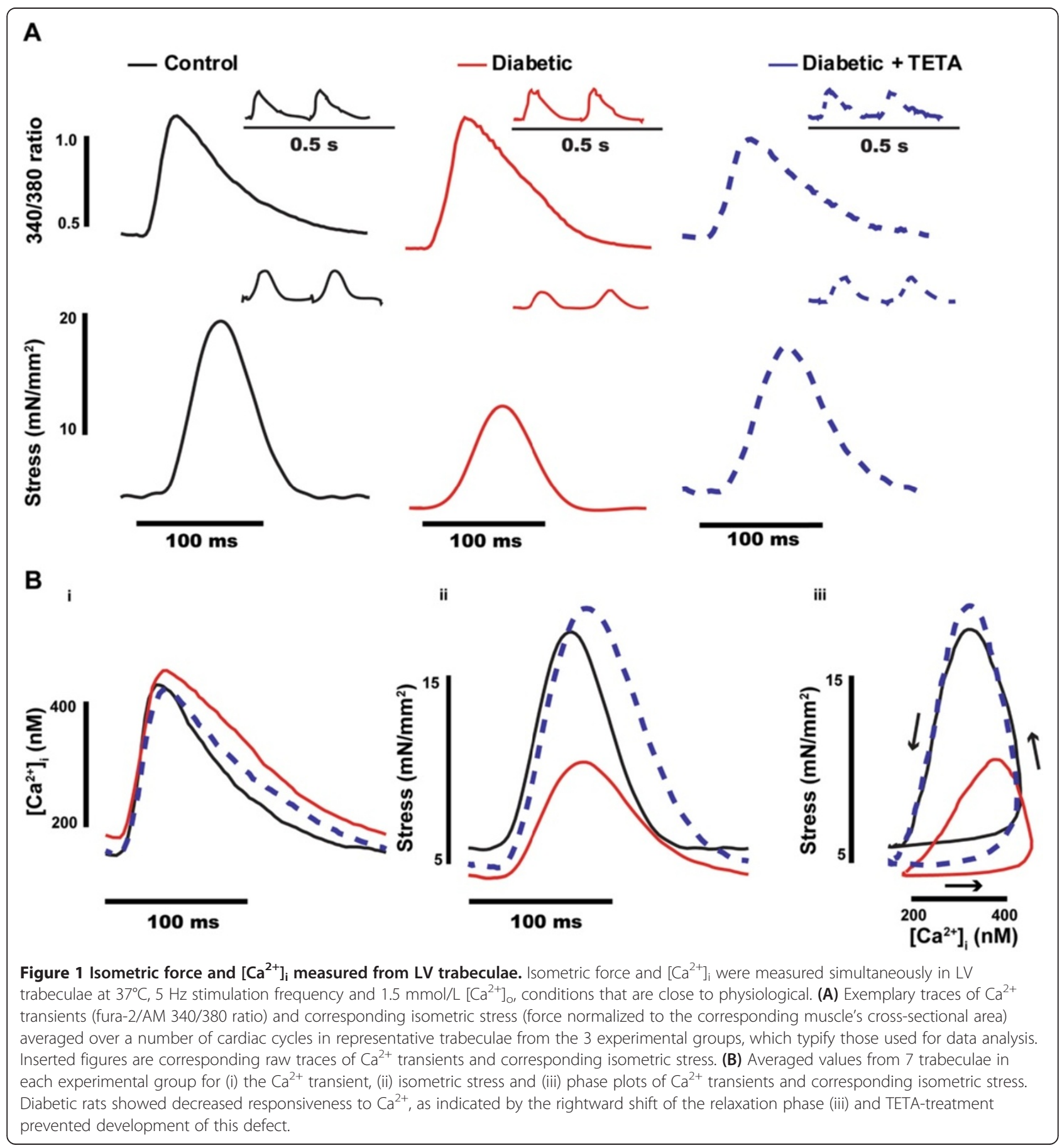




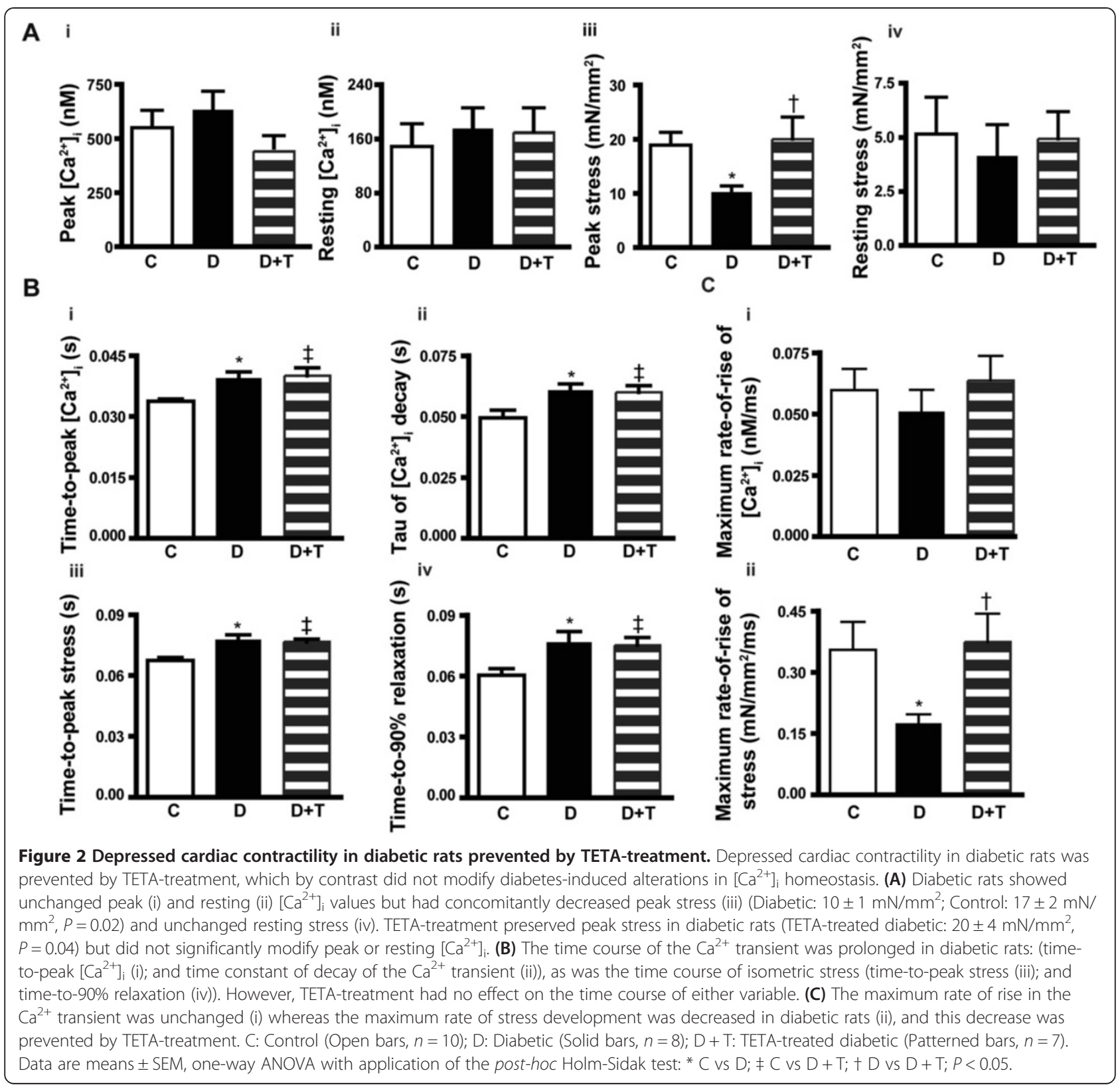

The relaxation-phase of isometric stress plotted against $\left[\mathrm{Ca}^{2+}\right]_{\mathrm{i}}$ showed a rightward-shift in diabetic rats, consistent with decreased myofibrillar $\mathrm{Ca}^{2+}$ sensitivity [57], whereas this effect was fully prevented by TETA (Figure 1Biii).

Although peak and resting levels of $\left[\mathrm{Ca}^{2+}\right]_{\mathrm{i}}$ were maintained in all experimental animals, diabetic rats had a prolonged time-course of their $\mathrm{Ca}^{2+}$ transients (increased time-to-peak $\left[\mathrm{Ca}^{2+}\right]_{\mathrm{i}}$ and time-constant of decay) compared to controls (both $P=0.02$, Figure $2 \mathrm{Bi}$, ii). Consistently, the time-course of contraction in diabetic rats was also slower (increased time-to-peak stress and time-to-90\% relaxation, $P=0.001$ and $P=0.025$, respectively, Figure 2Biii, iv). Moreover, TETA had no effect on the prolonged time-course of either the contraction or the $\mathrm{Ca}^{2+}$ transient in diabetic rats.

Decay of the $\mathrm{Ca}^{2+}$ transient in the rat is dominated by the rate of $\mathrm{Ca}^{2+}$ uptake by the sarcoplasmic reticulum via SERCA2a and, to a lesser extent by sarcolemmal $\mathrm{Ca}^{2+}$ extrusion via the $\mathrm{Na} / \mathrm{Ca}$ exchanger ( $\mathrm{NCX}, \sim 7-9 \%$ of total) [58]. Caffeine-induced $\mathrm{Ca}^{2+}$ transients were recorded and analyzed from LV cardiomyocytes to assess the activity of SERCA2a and NCX in the experimental groups. $10 \mathrm{mmol} / \mathrm{L}$ caffeine was used to eliminate the SR storage of $\mathrm{Ca}^{2+}$ during the decay of the $\mathrm{Ca}^{2+}$ transient, while $10 \mathrm{mmol} / \mathrm{L}\left[\mathrm{Ni}^{2+}\right]_{\mathrm{o}}$ and $0 \mathrm{mmol} / \mathrm{L}\left[\mathrm{Na}^{+}\right]_{\mathrm{o}}$ were used to further eliminate the contribution of NCX to 
the decay of the $\mathrm{Ca}^{2+}$ transient. Results (Figure 3A) showed no significant difference in the time-constant of decay of caffeine-induced $\mathrm{Ca}^{2+}$ transients among groups in any of the perfusion solutions. In comparison with the slower time-constant of decay of normal $\mathrm{Ca}^{2+}$ transients in diabetic rats, the unaltered caffeineinduced $\mathrm{Ca}^{2+}$ transients indicate that SERCA2a activity was down-regulated whereas NCX activity was unchanged. These findings are consistent with the Westernblotting study (Figure 3B), in which diabetic rats showed lower levels of SERCA2a $(P=0.01)$, whereas NCX was unaltered. These results could explain the slower decay of the $\mathrm{Ca}^{2+}$ transient in diabetic trabeculae. TETA had no significant effect on the expression of these proteins, consistent with the unchanged decay-rate of the $\mathrm{Ca}^{2+}$ transient in TETA-treated diabetic rats.

The unchanged levels of peak and resting $\left[\mathrm{Ca}^{2+}\right]_{\mathrm{i}}$ coupled with the slower kinetics of the $\mathrm{Ca}^{2+}$ transient cannot explain the depressed cardiac contractility in diabetic rats [32], since these alterations would favour increased force production, which was not observed here. We therefore hypothesized that altered $\left[\mathrm{Ca}^{2+}\right]_{\mathrm{i}}$ handling may not be the primary contributor to diabetes-evoked cardiac dysfunction, and that diabetic rats may have intrinsic myocardial defects that contribute to their depressed cardiac contractility. Our observations invited further investigation of myofibrillar $\mathrm{Ca}^{2+}$ sensitivity and cardiac remodelling in diabetic rat hearts.

TETA prevented the development of abnormal myofibrillar $\mathrm{Ca}^{2+}$ sensitivity in diabetic hearts The rightwardshift in the relaxation component of the phase-plot of isometric stress and $\left[\mathrm{Ca}^{2+}\right]_{\mathrm{i}}$ in diabetic rats (Figure 1Biii), is consistent with decreased myofibrillar $\mathrm{Ca}^{2+}$ sensitivity. TETA prevented this rightward-shift, suggesting that myofibrillar $\mathrm{Ca}^{2+}$ sensitivity was preserved in the drugtreated diabetic animals, contributing to their normal cardiac contractility. However, the rapid change in the $\mathrm{Ca}^{2+}$ transient during a normal twitch does not favour full development of the interaction between myofilaments and $\left[\mathrm{Ca}^{2+}\right]_{\mathrm{i}}$. We therefore investigated the steadystate force- $\left[\mathrm{Ca}^{2+}\right]_{\mathrm{i}}$ relationship to assess the role of $\mathrm{Ca}^{2+}$ in modulating force production under these conditions. Trabeculae were treated with $5 \mu \mathrm{mol} / \mathrm{L}$ ryanodine and high stimulation-frequency $(12 \mathrm{~Hz}, 6 \mathrm{~s})$ to induce cardiac tetanus for investigation of the steady-state force- $\left[\mathrm{Ca}^{2+}\right]_{\mathrm{i}}$ relationship (Figure 4A) [59]. During each tetanus, stress plateaued 3-4 s after the onset of stimulation, while $\left[\mathrm{Ca}^{2+}\right]_{\mathrm{i}}$ increased throughout. Tetanized stress and $\left[\mathrm{Ca}^{2+}\right]_{\mathrm{i}}$ increased with increasing $\left[\mathrm{Ca}^{2+}\right]_{\mathrm{o}}$ until maximum stress was reached: that is, increase in stress ceased even if $\left[\mathrm{Ca}^{2+}\right]_{\mathrm{i}}$ continued to increase. Measurement of stress and $\left[\mathrm{Ca}^{2+}\right]_{\mathrm{i}}$ were obtained $4 \mathrm{~s}$ after stimulation onset for each $\left[\mathrm{Ca}^{2+}\right]_{\mathrm{o}}$ level and values were fitted with the Hill equation (see Figure 4B, pooled data summarized in Table 2). Diabetic rats showed depression of maximum $\mathrm{Ca}^{2+}$-activated contractility to $\sim 47 \%$ of control values $(P=0.008)$ whereas TETA-treatment preserved the maximum contractility in treated-diabetic animals $(P=0.03)$. Untreated-diabetic rats also showed increased $K_{1 / 2}$ (the value of $\left[\mathrm{Ca}^{2+}\right]_{i}$ when half the maximum stress was reached), consistent with decreased myofibrillar $\mathrm{Ca}^{2+}$ sensitivity $(P=0.012)$. TETA prevented this alteration of $K_{1 / 2}$, suggesting that drug-treated diabetic rats have normal myofibrillar $\mathrm{Ca}^{2+}$ sensitivity compared to untreated ones $(P=0.05)$. Furthermore, the phase-plot between $\left[\mathrm{Ca}^{2+}\right]_{\mathrm{i}}$ and tetanus at $20 \mathrm{mmol} / \mathrm{L}\left[\mathrm{Ca}^{2+}\right]_{\mathrm{o}}$ from a number of trabeculae in each experimental group (Figure 4D) demonstrated a right-shifted relaxation phase in diabetic rats consistent with decreased myofibrillar $\mathrm{Ca}^{2+}$ sensitivity, which was prevented by TETA.

In addition to the conventional method of obtaining individual data points for $\left[\mathrm{Ca}^{2+}\right]_{\mathrm{i}}$ and stress at each $\left[\mathrm{Ca}^{2+}\right]_{\mathrm{o}}$ value to fit by the Hill equation, we analyzed phase-plots between $\left[\mathrm{Ca}^{2+}\right]_{\mathrm{i}}$ and tetanic force corresponding to a series of $\left[\mathrm{Ca}^{2+}\right]_{\mathrm{o}}$ levels (Figure $4 \mathrm{C}$ ). Values obtained during the rising phase of the phase-plots represented the maximum force produced by a trabecula at a particular $\left[\mathrm{Ca}^{2+}\right]_{\mathrm{i}}$ value. Comparisons between the slopes of the initial portion of the phase-plots from the three different experimental groups provides an indication of the dependence of cardiac contractility on $\left[\mathrm{Ca}^{2+}\right]_{\mathrm{i}}$. Diabetic rats had decreased slopes compared to controls (diabetic $0.7 \pm 0.2$, $n=7$ vs control $2.2 \pm 0.5, n=9, P=0.02)$, and TETA prevented this reduction (TETA-treated diabetic $5 \pm 2.1$, $n=7, P=0.05)$. This finding is consistent with that obtained using the conventional Hill equation fitting method (Figure 4B, Table 2).

Myofibrillar $\mathrm{Ca}^{2+}$ sensitivity is not only determined by the binding affinity of $\mathrm{Ca}^{2+}$ to troponin $\mathrm{C}(\mathrm{TnC})$ but also affected by the phosphorylation status of the troponin complex (comprising TnI, TnT, and tropomyosin), by the cooperation between the troponin complex and F-actin, and by force generation via binding of crossbridges. Alterations in protein expression of TnT [60] and $\mathrm{TnI}$ [61], or changes in their phosphorylation status [62] have been reported to occur in diabetic cardiomyopathy in association with decreased myofibrillar $\mathrm{Ca}^{2+}$ sensitivity. Here, we found that there were no significant differences in levels of $\mathrm{Tn} \mathrm{T}$ or $\mathrm{TnI}$ between diabetic and control LV myocardium (Figure 4E). In addition, TETA had no measurable effects on the expression level of these proteins in diabetic hearts. However, the proportion of phosphorylated TnI (Figure 5i) was increased in diabetic myocardium compared with control values (diabetic vs controls, $P<0.01$ ), which could contribute to their decreased myofibrillar $\mathrm{Ca}^{2+}$ sensitivity. By contrast, TETA treatment maintained the phosphorylation of TnI at normal levels (diabetic vs TETA-treated 


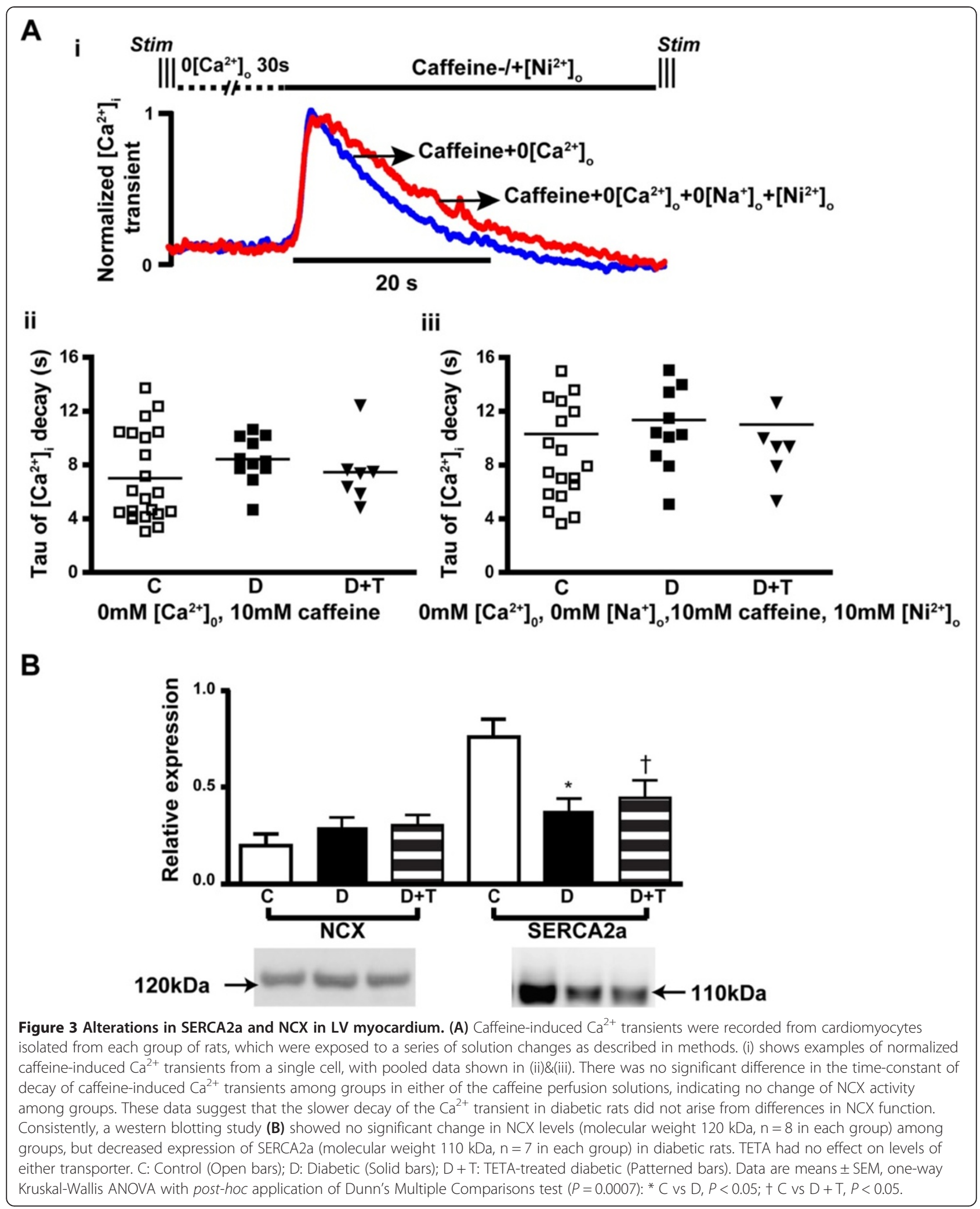




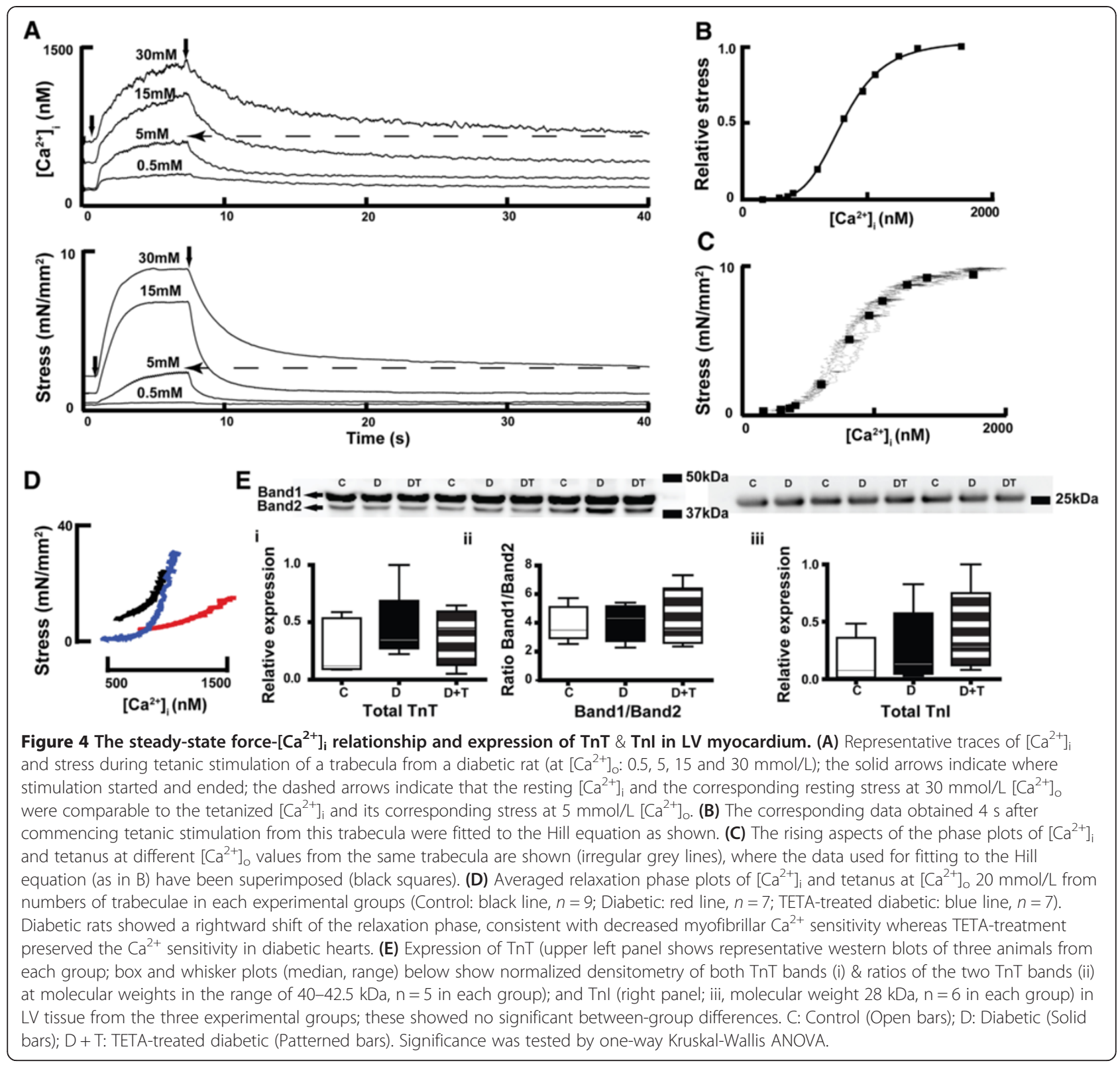

Table 2 Values obtained by fitting the Hill equation to the stated number of trabeculae in each group

\begin{tabular}{lccc}
\hline & Control & Diabetic & $\begin{array}{c}\text { TETA-treated } \\
\text { diabetic }\end{array}$ \\
\hline Number & 9 & 7 & 7 \\
Maximum stress $\left(\mathbf{m N} / \mathbf{m m}^{2}\right)$ & $38 \pm 4$ & $18 \pm 4^{\mathrm{a}}$ & $39 \pm 8^{\mathrm{b}}$ \\
Hill coefficient (N) & $6.3 \pm 1.2$ & $5.1 \pm 0.9$ & $8.4 \pm 1.6$ \\
$\mathbf{K}_{\mathbf{1} / \mathbf{2}}$ (nmol/L) & $688 \pm 60$ & $1018 \pm 105^{\mathrm{c}}$ & $799 \pm 37$
\end{tabular}

Data are means \pm SEM. $P$-values were determined by Kruskal-Wallis one-way ANOVA with post-hoc Dunn's Multiple-Comparisons tests: ${ }^{a}$, Diabetic vs Control groups, $P=0.008 ;{ }^{b}$, Diabetic vs TETA-treated diabetic rats, $P=0.03{ }^{c}{ }^{c}$, Diabetic vs Control rats, $P=0.012$. diabetic, $P<0.05)$, therefore preventing the reduction of the myofibrillar $\mathrm{Ca}^{2+}$ sensitivity. In addition, neither diabetes nor TETA treatment modified the phosphorylation of TnT (Figure 5ii).

TETA prevented structural deterioration of cardiac muscle Diabetic rats showed decreased LV free-wall thickness and increased intramural collagen labelling compared to control animals (Figure 6A, diabetic: $3.3 \pm$ $0.4 \mathrm{~mm}, n=8$ vs control: $5.3 \pm 0.3 \mathrm{~mm}, n=8, P=0.002$ ). Quantification showed an average increase of $14 \%$ in type-I collagen per cross-sectional area $(P=0.003)$ in diabetic hearts, without significant change in type-III collagen area (Figure 7C). Diabetic hearts also showed disorganized F-actin (Figure 6Bii), with significantly 


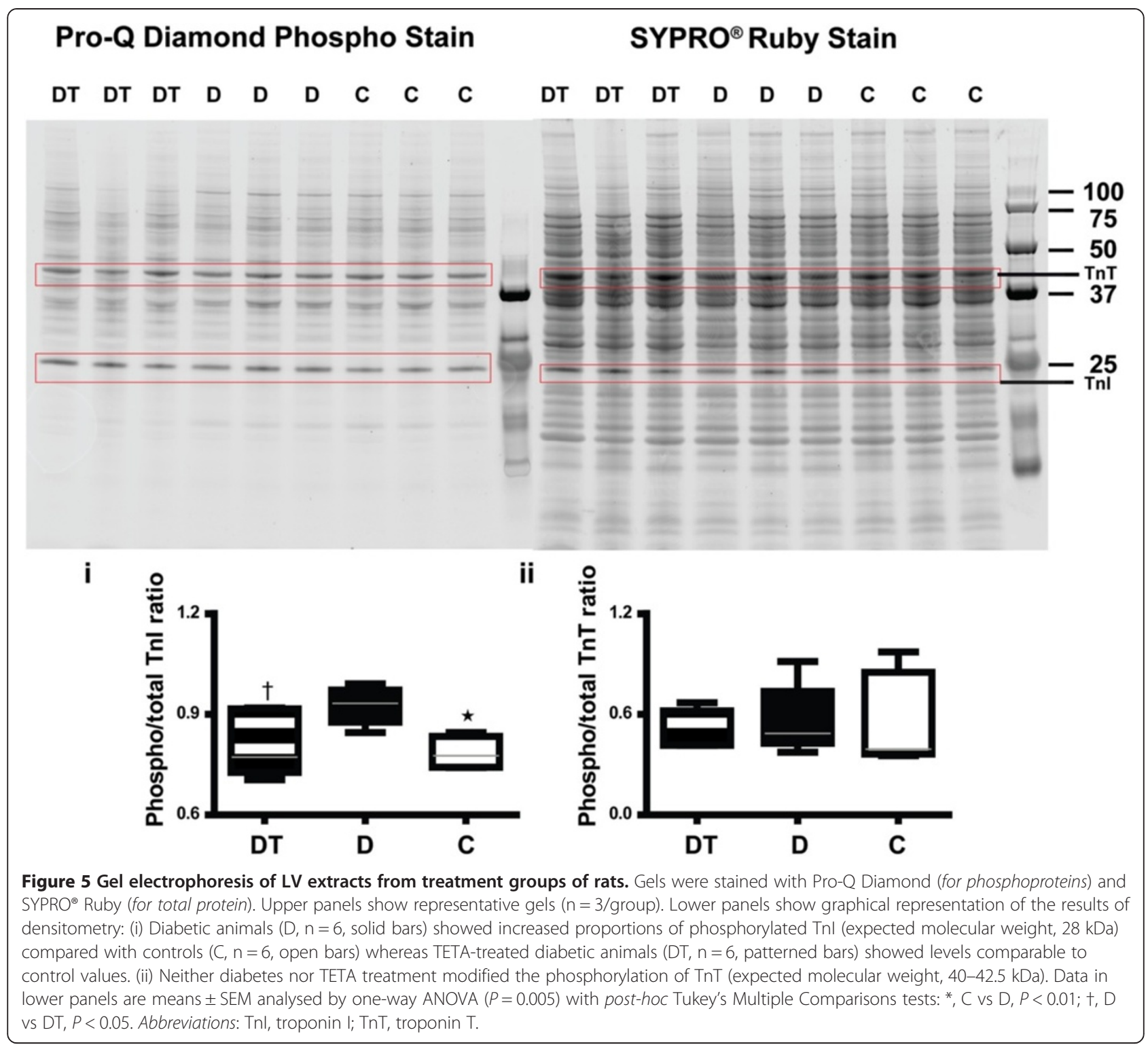

decreased (by $\sim 8 \%$ ) content of F-actin $(P<0.0001$, Figure $7 C$ ). TETA prevented the increase in type-I collagen labelling in diabetic hearts $(P=0.008$, Figure $7 \mathrm{C})$, and also prevented the disruption in F-actin to a significant extent $(P<0.0001$, Figures 6Biii, $7 C)$. These responses may account, at least in part, for TETA's ability to prevent cardiac dysfunction.

\section{Discussion}

In consideration of the importance of intracellular $\mathrm{Ca}^{2+}$ in the regulation of the cardiac contraction cycle, and reports of altered $\left[\mathrm{Ca}^{2+}\right]_{\mathrm{i}}$ homeostasis in diabetes [30-32], we have determined whether TETA could exert its inotropic effects through modulation of myocellular $\left[\mathrm{Ca}^{2+}\right]_{\mathrm{i}}$. We also sought to understand the relationship between perturbations in the myocardial homeostasis of calcium and of copper in diabetes, and the effects of TETA treatment on both.

We report here that diabetes lowered the total copper content of LV myocardium in rats by $\sim 50 \%$ as determined by PIXE, consistent with a recent finding [63], whereas TETA-treatment restored the total myocardial copper content to normal. We also show that TETA treatment prevented the onset of cardiac dysfunction in diabetic rats despite their sustained hyperglycaemia (> $30 \mathrm{mmol} / \mathrm{L}$ ), decreased body-weight and increased water consumption throughout the study, all of which are consistent with severe diabetes (Table 1).

In addition, TETA prevented the diabetes-evoked prolongation of the $\mathrm{QT}_{\mathrm{c}}$ interval. $\mathrm{QT}_{\mathrm{c}}$ prolongation may presage increased risk of macrovascular disease and fatal cardiac arrhythmias in diabetic patients [64], and also 


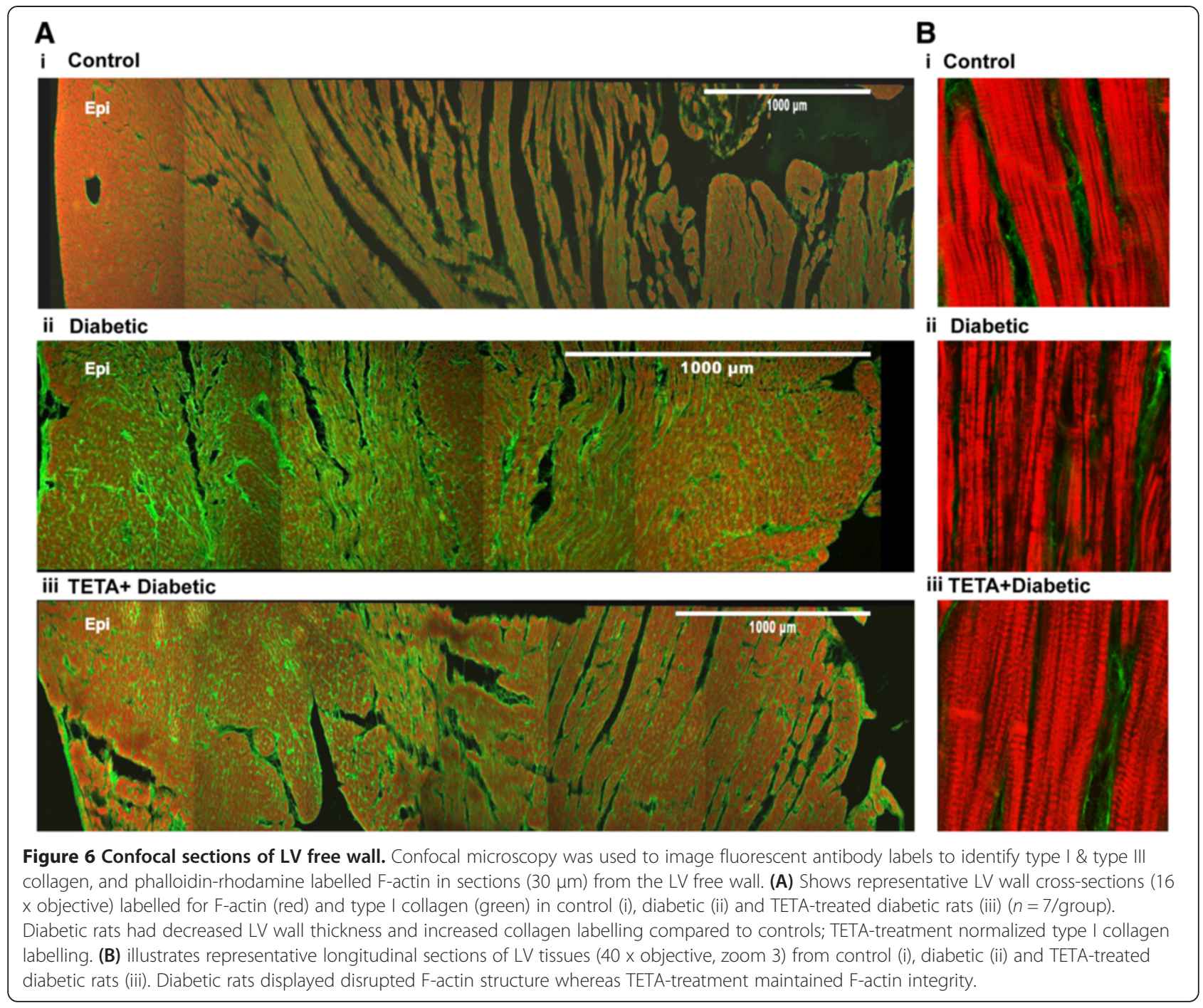

occurs in animals with cardiomyopathy caused by copper deficiency $[13,65]$. The observed correction of the $\mathrm{QT}_{\mathrm{c}}$ interval in diabetic cardiomyopathy coincided with normalization of myocardial copper regulation by TETA, and could signal improvement in the electrophysiological and mechanical properties of the heart following treatment. We have previously shown that TETA treatment of non-diabetic rats, at doses equivalent to those employed in diabetic animals, had no discernible effect on cardiac structure or function [23]. Therefore, the effects of TETA treatment in non-diabetic rats were not studied further in the current work.

Here, diabetic rats showed altered $\left[\mathrm{Ca}^{2+}\right]_{\mathrm{i}}$ regulation as reflected in the prolonged time-to-peak $\left[\mathrm{Ca}^{2+}\right]_{\mathrm{i}}$ and timeconstant of decay of the $\mathrm{Ca}^{2+}$ transient (Figure 2Bi, ii), consistent with published reports [30,31]. The measured decrease in expression of SERCA2a and its activity in these diabetic rats (Figure 3B) may well explain the slower decay of the $\mathrm{Ca}^{2+}$ transient. It would be expected to lower
SR $\mathrm{Ca}^{2+}$ uptake and release, thus decreasing the amplitude of the $\mathrm{Ca}^{2+}$ transient. However, this effect was offset by either the prolonged action-potential duration $\left(\mathrm{QT}_{\mathrm{c}}\right.$ interval) observed in these diabetic rats through increasing the sarcolemmal $\mathrm{Ca}^{2+}$ influx; or by the increase of $\mathrm{Ca}^{2+}$ influx via NCX during the diastolic period due to increased $\left[\mathrm{Na}^{+}\right]_{\mathrm{i}}$ [32]; or both. These ultimately resulted in the unchanged amplitude of the $\mathrm{Ca}^{2+}$ transient (Figure 2Ai, ii). Normal amplitude of the $\mathrm{Ca}^{2+}$ transient with slower kinetics would be expected to favour force production, but this was not the case here. On the contrary, depressed peak stress was observed in the untreated-diabetic rats. This finding is consistent with the hypothesis that altered $\left[\mathrm{Ca}^{2+}\right]_{\mathrm{i}}$ handling may not be the primary contributor to the depressed cardiac contractility in diabetic rats, and that TETA protects cardiac function by influencing variables other than $\left[\mathrm{Ca}^{2+}\right]_{\mathrm{i}}$.

Indeed, diabetic rats displayed decreased myofibrillar $\mathrm{Ca}^{2+}$ sensitivity (Figures 1Biii, 4D; Table 2), which may 


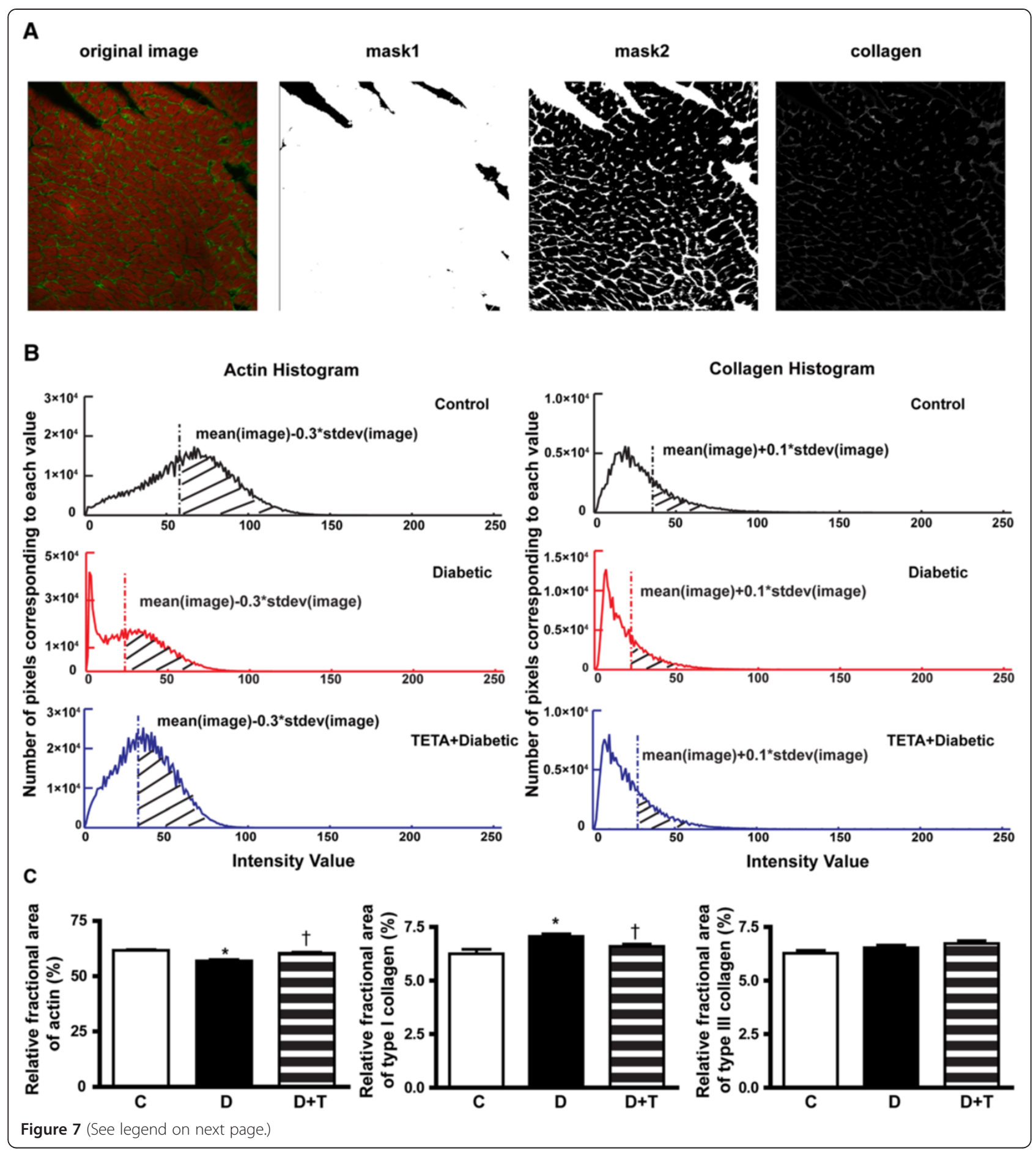


(See figure on previous page.)

Figure 7 Quantification of collagen and F-actin. Quantification of collagen and F-actin were based on signal thresholding of matched LV endocardial areas from each group ( $n=7$ per group). To avoid possible effects of orientation and origin of the muscle fibres on the quantification, three transverse optical sections per animal were analyzed. Results have been expressed as percentages of corresponding crosssectional areas. (A) A representative image illustrating application of the signal thresholding procedure. Mask1 eliminated the unlabelled area; mask2 additionally removed the F-actin labelled area. (B) Histogram of representative images from the three experimental groups showing the thresholds used for quantification. The criteria used for the thresholding process were maintained the same for each of the three experimental groups. The threshold setup for quantifying F-actin labelling was based on both the original image and the image following application of mask1. The threshold setup for quantifying collagen labelling was based on both the original image and the image after application of both mask1 and mask2. Shadowed areas represent signals used for quantification. (C) Results show that diabetic rats had increased type-I collagen content compared to controls (Diabetic: $7.1 \pm 0.1 \%$ area; Control: $6.2 \pm 0.2 \%$ area, $P=0.003$ ), and TETA prevented this increase by retaining normal values (TETA-treated diabetic: $6.6 \pm 0.1 \%$ area, $P=0.008$ ). Diabetic rats also developed lowered F-actin content compared to control rats (Diabetic: $56.9 \pm 0.6 \%$ area; Control: $61.7 \pm 0.4 \%$ area, $P<0.0001$ ); whereas, TETA-treatment prevented the lowering of F-actin values (TETA-treated diabetic: $60.4 \pm 0.5 \%$ area, $P<0.0001$ ). Type-III collagen did not differ significantly between groups. Data are means \pm SEM, one-way ANOVA with post-hoc Tukey's Multiple Comparisons test. ${ }^{*} \mathrm{C}$ vs $\mathrm{D} ;+\mathrm{D}$ vs $\mathrm{D}+\mathrm{T} ; \mathrm{P}<0.05$

partly account for their depressed cardiac contractility, whereas TETA prevented this decrease from developing. In our study, we used intact muscle preparations to assess myofibrillar $\mathrm{Ca}^{2+}$ sensitivity at physiological temperature. Compared with skinned heart-muscle fibres or cells [66-69], in which the surface membrane has been permeabilized, our preparations kept the intracellular environment intact, thus avoiding the possibility that myofibrillar $\mathrm{Ca}^{2+}$ sensitivity was affected by perturbations in the intracellular environment. For example, disruptions of physiologically-occurring cytosolic factors such as hydrogen and phosphate ion levels would affect the sensitivity of myofilaments to $\mathrm{Ca}^{2+}[68,69]$.

Our use of intact, ryanodine-treated LV trabeculae consistently produced tetani at different $\left[\mathrm{Ca}^{2+}\right]_{\mathrm{o}}$ levels (Figure 4). Upon tetanic stimulation, $\left[\mathrm{Ca}^{2+}\right]_{\mathrm{i}}$ rose steadily throughout whereas force plateaued and thereafter remained constant (Figure 4A), indicating that maximal $\mathrm{Ca}^{2+}$-activated force had been reached. At high levels of $\left[\mathrm{Ca}^{2+}\right]_{o}$, the resting $\left[\mathrm{Ca}^{2+}\right]_{i}$ was elevated in comparison to that at lower $\left[\mathrm{Ca}^{2+}\right]_{\mathrm{o}}$, suggesting the possibility of increased intracellular $\left[\mathrm{H}^{+}\right]$. However, when comparisons were made between the resting force at high $\left[\mathrm{Ca}^{2+}\right]_{\mathrm{o}}$ and the peak tetanic force at low $\left[\mathrm{Ca}^{2+}\right]_{\mathrm{o}}$, they were comparable for similar $\left[\mathrm{Ca}^{2+}\right]_{\mathrm{i}}$. For example, in Figure $4 \mathrm{~A}$ (dashed line), the resting force at $30 \mathrm{mmol} / \mathrm{L}\left[\mathrm{Ca}^{2+}\right]_{\mathrm{o}}$ was comparable to the tetanic force at $5 \mathrm{mmol} / \mathrm{L}\left[\mathrm{Ca}^{2+}\right]_{\mathrm{o}}$. This indicates that high $\left[\mathrm{Ca}^{2+}\right]_{0}$ evoked either no, or at most minor changes in intracellular $\left[\mathrm{H}^{+}\right]$, which would be unlikely to affect trabecular force production.

Normally, tension development is initiated by $\mathrm{Ca}^{2+}$ binding to $\mathrm{TnC}$, which triggers a series of reversible interactions and structural changes among the proteins of the thin filaments (TnI, TnT and Tm), therefore exposing the myosin binding sites on actin to enable crossbridge formation. As a result of the cooperative nature of this process, a decreased propensity of $\mathrm{Ca}^{2+}$ binding to evoke the conformational changes of these proteins and cross-bridge formation would eventually affect force development. Alterations in the relative expression of $\mathrm{TnT}$ isoforms have been demonstrated, coincident with diminished $\mathrm{Ca}^{2+}$ sensitivity of skinned cardiac-muscle contractility in diabetic rats [60]. Here, we found that neither diabetes nor TETA affected cardiac levels of $\mathrm{TnT}$ and its isoforms (Figure 4E). This between-study difference may well have been caused by different experimental conditions and the disease stages used in different studies: for example, the animals in the above study had been diabetic for substantially longer than ours. Although unchanged expression levels of TnI have been reported in diabetic hearts with diminished $\mathrm{Ca}^{2+}$ sensitivity [70], consistent with this report (Figure 4E), others have reported down-regulation of $\mathrm{TnI}$ in conjunction with diminished $\mathrm{Ca}^{2+}$ sensitivity in a cardiac actomyosin system reconstituted with regulatory-protein complexes from diabetic hearts [61]. This further between-study difference may be attributable to differences in the experimental conditions. However, in our diabetic animals, the phosphorylation ratio of $\mathrm{TnI}$ was increased (Figure 5i) which may account for their decreased myofibrillar $\mathrm{Ca}^{2+}$ sensitivity. TETA treatment maintained the phosphorylation level of $\mathrm{TnI}$ in treated diabetic animals, therefore contributing to their normal $\mathrm{Ca}^{2+}$ sensitivity. The altered phosphorylation states of one or more of the contractile proteins perhaps reflect increased protein kinase $\mathrm{C}$ (PKC) activity [71]. This is confirmed by our previous report that myocardial $\mathrm{PKC}_{\delta}$ gene expression is increased by $\sim 30 \%$ in diabetic myocardium [72]. $\mathrm{PKC}_{\delta}$ is uniquely able to phosphorylate Ser23/Ser24 in troponin I; and consequently, like protein kinase A (PKA), it can reduce myofilament $\mathrm{Ca}^{2+}$ sensitivity [73].

We have previously reported that, in this animal model, the expression of mRNA corresponding to $\beta$-myosin heavy-chain undergoes a $\sim 50 \%$ increase in LV tissues, whereas that of $\alpha$-myosin heavy chain is decreased to $\sim 35 \%$ of control values [72]. However, TETA treatment had no significant effect on the expression of either $\alpha$-myosin or $\beta$-myosin heavy chains in the myocardium of these 
diabetic animals (Cooper GJ et al., unpubl. data). This would exclude the contribution of changes in the expression of myosin isoforms to TETA's inotropic effect.

Further, we report here that diabetes decreases total myocardial copper to markedly-lowered values, whereas we previously showed increases in the systemic and cardiac $\mathrm{Cu}(\mathrm{II})$ in the same diabetic model, as can be extracted by intra-arterial infusion of TETA. The excess $\mathrm{Cu}(\mathrm{II})$ is likely to be bound in the ECM $[23,25]$ since copper is mainly ( 95\%) present in the intracellular compartment as $\mathrm{Cu}(\mathrm{I})$ and the remaining $\sim 5 \%$ is in the extracellular space as $\mathrm{Cu}$ (II) $[74,75]$. While increased extracellular $\mathrm{Cu}$ (II) can promote oxidative stress by generating hydroxyl radicals [8], decreased myocardial copper can also act to cause prooxidant stress by impairing antioxidant defences mediated by copper-enzymes, for example lowered activity of endothelial EC-SOD and plasma ferroxidase [25,29,76]. These effects are all reversible by TETA-treatment $[25,29,76]$. In addition, we have shown at the protein level that TETA can lower ROS production by reversing the impaired expression of mitochondrial proteins involved in their production in diabetic LV tissue [77]. The increased oxidative stress in diabetic rats can lead to increased levels of oxidized-glutathione, further contributing to decreased $\mathrm{Ca}^{2+}$ sensitivity [78], which is confirmed by our previous study showing that mRNAs corresponding to several enzymes regulating aspects of glutathione metabolism were altered in diabetic cardiomyopathy [72]. Thus TETA treatment can bolster antioxidant defences in diabetic animals [29], thereby contributing to maintenance of myocardial $\mathrm{Ca}^{2+}$ sensitivity.

Myocardial copper deficiency is a known cause of myocardial fibrosis and cardiac failure $[12,13,15,16]$. Our findings suggest that the relative distribution of the two copper valence states has become dysregulated in diabetic cardiomyopathy. While total myocardial $\mathrm{Cu}$ level was decreased in diabetic cardiomyopathy, systemic and cardiac $\mathrm{Cu}$ (II) levels were increased [23,25]. This phenomenon is different from that in dietary copper restriction-induced cardiomyopathy, where both myocardial and systemic copper levels are decreased $[13,15]$. Interestingly, there is a report that, in a heart-specific knockout of Ctr1, cardiomyopathy induced by lack of myocardial copper transport led to decreased copper accumulation in cardiac tissue, accompanied by an unexpected increase in serum copper levels [79]. The authors suggested that peripheral organs may communicate with copper acquisition and storage organs through an unknown mechanism. This finding indicates the need for further studies on copper transport and its regulation in different organ systems in our diabetic animal models, to improve understanding of copper regulation in diabetes and in association with the response to TETA treatment.
Consistent with our previous reports [23,32], cardiac remodelling in diabetic rats was also observed in this study, as shown by the increased collagen content and disrupted F-actin in LV tissue (Figures 6, 7). We previously demonstrated regeneration of cardiac structure by TETA after cardiomyopathy had been present for several weeks [23]. By contrast, we show here that TETA prevented the development of cardiomyopathy and remodelling when administered $a b$ initio. The increased collagen content and disrupted F-actin in diabetic hearts could in part account for the depressed cardiac contractility and decreased myofibrillar $\mathrm{Ca}^{2+}$ sensitivity observed therein (Figures 1, 2). TETA significantly prevented excessive collagen deposition and F-actin disruption, thereby maintaining muscle integrity in diabetic hearts (Figures 6, 7), which could account for its prevention of defective myocardial contractility and $\mathrm{Ca}^{2+}$ sensitivity. The mechanisms underlying this suppression of cardiac remodelling may be attributable to the impaired activity of endothelial EC-SOD and plasma ferroxidase in our STZ-diabetic animals. These impairments could cause myocardial fibrosis via excessive TGF- $\beta /$ SMAD signaling. However, these effects are reversible by TETA-treatment $[25,76]$. Our previous data indicate that TETA action may suppress the pathogenic activation of a myocardial TGF- $\beta$ /SMAD signalling pathway that in turn mediates the expression of genes encoding extracellular matrix (ECM) proteins and ECM-degrading enzymes $[80,81]$, by restoration of normal EC-SOD regulation.

This study has potential limitations. Some workers have suggested that the cardiomyopathy in STZ-diabetic rats may reflect, at least in part, direct myocardial toxicity of the drug in addition to the effects of diabetes per se. However, we have validated the STZ-based model we used here by showing that these diabetic rats respond both to untreated diabetes and following TETA treatment, in ways that closely reflect responses in patients with T2D [21-24,28]. To date, we have shown that TETA treatment exerts substantive effects to restore LV mass in patients with LVH [24]. There are large gaps in current understanding of diabetes-mediated effects on the molecular regulation of myocardial copper homeostasis, and the molecular basis of its restoration by TETA treatment. Studies to clarify these issues are clearly required. Furthermore, there are newly described mechanisms influencing cardiomyocyte function that may act in parallel with defective copper regulation. For instance, $\mathrm{Zn}^{2+}$-mediated effects on myocardial relaxation are more pronounced in the hyperglycaemic state, possibly due an insulin-dependent effect in enhancing sequestration of $\left[\mathrm{Ca}^{2+}\right]_{\mathrm{i}}$ via SERCA2a [63]. The peptide obestatin, which is encoded by the ghrelin gene, upregulates the transcription of myocardial $\beta_{1}$-adrenergic 
receptors [82]. Moreover, alpha-lipoic acid diminishes interstitial fibrosis by decreasing collagen deposition [83]. These three effects are endogenous in mammals and may represent potentially confounding mechanisms when evaluating myocardial function. Whether any of these other factors will ultimately prove to be of clinical significance awaits the introduction of interventions based on these processes into informative clinical trials.

In this study, we have relied upon the high degree of specificity of $\mathrm{Cu}^{2+}$-TETA binding $[25,26]$, as well as direct measurements of myocardial copper by PIXE, and our prior quantitative studies of systemic copper homeostasis, to support the role of copper in the processes under study. The findings we have reported here are consistent with our recent study showing TETA-mediated reversal of LV dysfunction in diabetic rats in vivo [28]. However, there are as yet no published data showing that TETA treatment can suppress overt heart failure in diabetic patients. Furthermore, in order to establish the validity of TETA treatment for this condition, it will be necessary to show that it has a clinically significant beneficial effect on important outcomes such as mortality and/ or hospitalization. Such data are not yet available.

In conclusion, we report here that TETA-treatment prevented the development of diabetes-induced cardiac dysfunction without modifying elevated circulating blood glucose levels, thereby breaking the link between hyperglycaemia and myocardial damage. Our data support the hypothesis that altered $\left[\mathrm{Ca}^{2+}\right]_{\mathrm{i}}$ handling is unlikely to be the primary contributor to cardiac dysfunction in diabetes. The maintenance of normal cardiac contractility in TETA-treated diabetic rats may be attributable to chelator-mediated prevention of deterioration in myofibrillar $\mathrm{Ca}^{2+}$ sensitivity and cardiac muscle structure. The molecular basis of TETA function requires further elucidation. We would note that it is already documented to repair mitochondrial structure-function, extracellular matrix integrity and myocardial contractile machinery via restoration of myocardial copper-catalysed antioxidant defences.

\footnotetext{
Abbreviations

$\left[\mathrm{Ca}^{2+}\right]_{i}$ : Intracellular ionic calcium concentration; $\mathrm{Cu}(\mathrm{II})$ : Divalent copper; EC: Extracellular; ECM: Extracellular matrix; F-actin: Filamentous actin; LV: Left ventricular; $\mathrm{Na}^{+}$: Sodium; $\mathrm{NCX}: \mathrm{Na}^{+} / \mathrm{Ca}^{2+}$ exchanger; $\mathrm{Ni}^{2+}$ : Nickel ion; PKA: Protein kinase A; PKC: Protein kinase C; ROS: Reactive oxygen species; SERCA: Sarco/endoplasmic reticulum $\mathrm{Ca}^{2+}$ ATPase; SOD: Superoxide dismutase; STZ: Streptozotocin; TETA: Triethylenetetramine; TnC: Troponin C; Tnl: Troponin I; TnT: Troponin T; T2D: Type-2 diabetes mellitus.
}

\section{Competing interests}

The authors declare no duality of interest associated with this manuscript.

\section{Authors' contributions}

LZ participated in study design, acquisition and analysis of data interpretation of results, and wrote the first draft of the manuscript; GC participated in study concept and design, data analysis and interpretation of results, and wrote manuscript drafts; AP and SZ participated in study concept and design, data analysis and interpretation of results; MW and MC participated in study design, data analysis and interpretation of results. All authors participated in critical revision and approved the final version of the manuscript. LZ and GC are the guarantors of this work and, as such, had full access to all of the data in the study and take responsibility for the integrity of the data and the accuracy of the data analysis. All authors read and approved the final manuscript.

\section{Acknowledgements}

We thank C. A. Tse (School of Biological Sciences, University of Auckland, New Zealand) for management/administrative assistance and John Scott for his helpful discussions, criticism and moral support.

\section{Funding}

Work on this programme has been funded by grants from Endocore Research Associates; the Maurice and Phyllis Paykel Trust; Lottery Health (New Zealand); the Auckland Medical Research Foundation; the University of Auckland; the Department of Education (New Zealand) through a grant to the Maurice Wilkins Centre of Excellence for Molecular Biodiscovery; by programme grants from the Ministry for Business, Innovation and Employment, New Zealand, and from the Health Research Council of New Zealand; and was facilitated by the Manchester Biomedical Research Centre and the Greater Manchester Comprehensive Local Research Network.

\section{Author details}

${ }^{1}$ School of Biological Sciences, Faculty of Science, University of Auckland, Private Bag 92019, Auckland 1142, New Zealand. 'Department of Physiology, Faculty of Medical and Health Sciences, University of Auckland, Auckland, New Zealand. ${ }^{3}$ Department of Surgery, Faculty of Medical and Health Sciences, University of Auckland, Auckland, New Zealand. ${ }^{4}$ National Isotope Centre, GNS Science, Gracefield, Wellington, New Zealand. ${ }^{5}$ Centre for Advanced Discovery and Experimental Therapeutics, Manchester Biomedical Research Centre, University of Manchester, Manchester, UK. ${ }^{6}$ Department of Pharmacology, Medical Sciences Division, University of Oxford, Oxford, UK.

${ }^{7}$ School of Physiology \& Pharmacology, Medical Sciences Building, University of Bristol, Bristol, BS8 1TD, UK.

Received: 20 June 2013 Accepted: 25 August 2013

Published: 28 August 2013

\section{References}

1. Bauters C, Lamblin N, Mc Fadden MP, Van Belle E, Millaire A, De Groote P: Influence of diabetes mellitus on heart failure risk and outcome. Cardiovasc Diabetol 2003, 2:1.

2. Sowers JR, Epstein M, Frohlich ED: Diabetes, hypertension, and cardiovascular disease: an update. Hypertension 2001, 37:1053-1059.

3. Rubler S, Dlugash J, Yuceoglu YZ, Kumral T, Branwood AW, Grishman A: New type of cardiomyopathy associated with diabetic glomerulosclerosis. Am J Cardiol 1972, 30(6):595-602.

4. Boudina S, Abel ED: Diabetic cardiomyopathy revisited. Circulation 2007, 115:3213-3223.

5. Struthers AD, Morris AD: Screening for and treating left-ventricular abnormalities in diabetes mellitus: a new way of reducing cardiac deaths. Lancet 2002, 359:1430-1432.

6. Shaw JE, Sicree RA, Zimmet PZ: Global estimates of the prevalence of diabetes for 2010 and 2030. Diabetes Res Clin Prac 2010, 87(1):4-14

7. Bertinato J, L'Abbe MR: Maintaining copper homeostasis: regulation of copper-trafficking proteins in response to copper deficiency or overload. J Nutr Biochem 2004, 15(6):316-322.

8. Halliwell B, Gutteridge JM: Oxygen toxicity, oxygen radicals, transition metals and disease. Biochem J 1984, 219(1):1-14.

9. Stacey NH, Klaassen CD: Comparison of the effects of metals on cellular injury and lipid peroxidation in isolated rat hepatocytes. $J$ Toxicol Environ Health 1981, 7(1):139-147.

10. Stacey $\mathrm{NH}$, Klaassen CD: Copper toxicity in isolated rat hepatocytes. Toxicol Appl Pharmacol 1981, 58(2):211-220.

11. Kopp SJ, Klevay LM, Feliksik JM: Physiological and metabolic characterization of a cardiomyopathy induced by chronic copper deficiency. Am J Physiol 1983, 245:H855-H866.

12. Prohaska JR, Heller $\mathrm{L}$ : Mechanical properties of the copper-deficient rat heart. J Nutr 1982, 112(11):2142-2150. 
13. Li Y, Wang L, Schuschke DA, Zhou Z, Saari JT, Kang YJ: Marginal dietary copper restriction induces cardiomyopathy in rats. J Nutr 2005, 135(9):2130-2136.

14. Elsherif L, Ortines RV, Saari JT, Kang YJ: Congestive heart failure in copperdeficient mice. Exp Biol Med (Maywood) 2003, 228(7):811-817.

15. Elsherif L, Wang L, Saari JT, Kang YJ: Regression of dietary copper restriction-induced cardiomyopathy by copper repletion in mice. J Nutr 2004, 134(4):855-860.

16. Jiang Y, Reynolds C, Xiao C, Feng W, Zhou Z, Rodriguez W, Tyagi SC, Eaton JW, Saari JT, Kang YJ: Dietary copper supplementation reverses hypertrophic cardiomyopathy induced by chronic pressure overload in mice. J Exp Med 2007, 204(3):657-666.

17. Dameron $C T$, Harrison MD: Mechanisms for protection against copper toxicity. Am J Clin Nutr 1998, 67(Suppl):1091S-1097S.

18. Bremner I: Manifestations of copper excess. Am J Clin Nutr 1998, 67 (Suppl):1069S-1073S

19. Uriu-Adams JY, Rucker RB, Commisso JF, Keen CL: Diabetes and dietary copper alter ${ }^{67} \mathrm{Cu}$ metabolism and oxidant defense in the rat. $J$ Nutr Biochem 2005, 16(5):312-320.

20. Failla ML, Kiser RA: Altered tissue content and cytosol distribution of trace metals in experimental diabetes. J Nutr 1981, 111(11):1900-1909.

21. Cooper GJ: Therapeutic potential of copper chelation with triethylenetetramine in managing diabetes mellitus and Alzheimer's disease. Drugs 2011, 71(10):1281-1320.

22. Cooper GJ: Selective divalent copper chelation for the treatment of diabetes mellitus. Curr Med Chem 2012, 19(17):2828-2860.

23. Cooper GJ, Phillips AR, Choong SY, Leonard BL, Crossman DJ, Brunton DH, Saafi L, Dissanayake AM, Cowan BR, Young AA, et al: Regeneration of the heart in diabetes by selective copper chelation. Diabetes 2004, 53(9):2501-2508.

24. Cooper GJ, Young AA, Gamble GD, Occleshaw CJ, Dissanayake AM, Cowan BR, Brunton DH, Baker JR, Phillips AR, Frampton CM, et al: A copper(II)-selective chelator ameliorates left-ventricular hypertrophy in type 2 diabetic patients: a randomised placebo-controlled study. Diabetologia 2009, 52(4):715-722.

25. Cooper GJ, Chan YK, Dissanayake AM, Leahy FE, Keogh GF, Frampton CM, Gamble GD, Brunton DH, Baker JR, Poppitt SD: Demonstration of a hyperglycemia-driven pathogenic abnormality of copper homeostasis in diabetes and its reversibility by selective chelation: quantitative comparisons between the biology of copper and eight other nutritionally essential elements in normal and diabetic individuals. Diabetes 2005, 54(5):1468-1476.

26. Nurchi VM, Crisponi G, Crespo-Alonso M, Lachowicz JI, Szewczuk Z, Cooper GJ: Complex formation equilibria of $\mathrm{Cu}(\mathrm{II})$ and $\mathrm{Zn}(\mathrm{II})$ with triethylenetetramine and its mono- and di-acetyl metabolites. Dalton Trans 2013, 42(17):6161-6170.

27. Siegemund R, Lossner J, Gunther K, Kuhn HJ, Bachmann H: Mode of action of triethylenetetramine dihydrochloride on copper metabolism in Wilson's disease. Acta Neurol Scand 1991, 83(6):364-366.

28. Lu J, Pontre B, Pickup S, Choong SY, Li M, Xu H, Gamble GD, Phillips AR, Cowan BR, Young AA, et al: Treatment with a copper-selective chelator causes substantive improvement in cardiac function of diabetic rats with left-ventricular impairment. Cardiovasc Diabetol 2013, 12:28.

29. Lu J, Gong D, Choong SY, Xu H, Chan YK, Chen X, Fitzpatrick S, Glyn-Jones S, Zhang S, Nakamura T, et al: Copper(II)-selective chelation improves function and antioxidant defences in cardiovascular tissues of rats as a model of diabetes: comparisons between triethylenetetramine and three less copper-selective transition-metal-targeted treatments. Diabetologia 2010, 53(6):1217-1226.

30. Pierce GN, Russell JC: Regulation of intracellular $\mathrm{Ca}^{2+}$ in the heart during diabetes. Cardiovasc Res 1997, 34(1):41-47.

31. Choi KM, Zhong Y, Hoit BD, Grupp IL, Hahn H, Dilly KW, Guatimosim S, Lederer WJ, Matlib MA: Defective intracellular $\mathrm{Ca}^{2+}$ signaling contributes to cardiomyopathy in Type 1 diabetic rats. Am J Physiol Heart Circ Physiol 2002, 283(4):H1398-H1408.

32. Zhang L, Cannell MB, Phillips AR, Cooper GJ, Ward ML: Altered calcium homeostasis does not explain the contractile deficit of diabetic cardiomyopathy. Diabetes 2008, 57(8):2158-2166.

33. Norby FL, Wold LE, Duan J, Hintz KK, Ren J: IGF-I attenuates diabetesinduced cardiac contractile dysfunction in ventricular myocytes. Am J Physiol Endocrinol Metab 2002, 283(4):E658-E666.

34. Ozdemir S, Ugur M, Gurdal H, Turan B: Treatment with $\mathrm{AT}_{1}$ receptor blocker restores diabetes-induced alterations in intracellular $\mathrm{Ca}^{2+}$ transients and contractile function of rat myocardium. Arch Biochem Biophys 2005, 435(1):166-174.
35. Yaras N, Ugur M, Ozdemir S, Gurdal H, Purali N, Lacampagne A, Vassort G, Turan B: Effects of diabetes on ryanodine receptor Ca release channel $\left(\mathrm{RyR}_{2}\right)$ and $\mathrm{Ca}^{2+}$ homeostasis in rat heart. Diabetes 2005, 54(11):3082-3088.

36. Howarth FC, Adem A, Adeghate EA, Al Ali NA, Al Bastaki AM, Sorour FR, Hammoudi RO, Ghaleb NA, Chandler NJ, Dobrzynski H: Distribution of atrial natriuretic peptide and its effects on contraction and intracellular calcium in ventricular myocytes from streptozotocin-induced diabetic rat. Peptides 2005, 26(4):691-700.

37. Howarth FC, Qureshi MA: Effects of carbenoxolone on heart rhythm, contractility and intracellular calcium in streptozotocin-induced diabetic rat. Mol Cell Biochem 2006, 289(1-2):21-29.

38. Howarth FC, Qureshi A, Singh J: Effects of acidosis on ventricular myocyte shortening and intracellular $\mathrm{Ca}^{2+}$ in streptozotocin-induced diabetic rats. Mol Cell Biochem 2004, 261(1-2):227-233.

39. Howarth FC, Qureshi MA, White E: Effects of hyperosmotic shrinking on ventricular myocyte shortening and intracellular $\mathrm{Ca}^{2+}$ in streptozotocininduced diabetic rats. Pflugers Arch 2002, 444(3):446-451.

40. Kotsanas G, Delbridge LM, Wendt IR: Stimulus interval-dependent differences in $\mathrm{Ca}^{2+}$ transients and contractile responses of diabetic rat cardiomyocytes. Cardiovasc Res 2000, 46(3):450-462.

41. Noda N, Hayashi H, Satoh H, Terada H, Hirano M, Kobayashi A, Yamazaki N: $\mathrm{Ca}^{2+}$ transients and cell shortening in diabetic rat ventricular myocytes. Jpn Circ J 1993, 57(5):449-457.

42. Lagadic-Gossmann D, Buckler KJ, Le Prigent K, Feuvray D: Altered Ca ${ }^{2+}$ handling in ventricular myocytes isolated from diabetic rats. Am J Physiol 1996, 270(5 Pt 2):H1529-H1537.

43. Yu JZ, Rodrigues B, McNeill JH: Intracellular calcium levels are unchanged in the diabetic heart. Cardiovasc Res 1997, 34(1):91-98.

44. Singh J, Chonkar A, Bracken N, Adeghate E, Latt Z, Hussain M: Effect of streptozotocin-induced type 1 diabetes mellitus on contraction, calcium transient, and cation contents in the isolated rat heart. Ann N Y Acad Sci 2006, 1084:178-190.

45. Wolff SP, Jiang ZY, Hunt JV: Protein glycation and oxidative stress in diabetes mellitus and ageing. Free Radic Biol Med 1991, 10(5):339-352.

46. Bidasee KR, Nallani K, Yu Y, Cocklin RR, Zhang Y, Wang M, Dincer UD, Besch HR Jr: Chronic diabetes increases advanced glycation end products on cardiac ryanodine receptors/calcium-release channels. Diabetes 2003, 52(7):1825-1836.

47. Committee for the Update of the Guide for the Care and Use of Laboratory Animals: Guide for the Care and Use of Laboratory Animals. Eighthth edition. Washington, D.C: Institute for Laboratory Animal Research, Division on Earth and Life Studies, National Research Council of the National Academies, The National Academies Press; 2011.

48. Kilkenny C, Browne WJ, Cuthill IC, Emerson M, Altman DG: Improving bioscience research reporting: the ARRIVE guidelines for reporting animal research. PLOS Biol 2010, 8(6):e1000412

49. Wichmann KA, Boyd PDW, Sohnel T, Allen GR, Phillips AR, Cooper GJ: Characterization of dicarboxylic salts of protonated triethylenetetramine useful for the treatment of copper-related pathologies. Cryst Growth Des 2007, 7(9):1844-1850.

50. Dahlman T, Hartvig P, Lofholm M, Nordlinder H, Loof L, Westermark K Long-term treatment of Wilson's disease with triethylene tetramine dihydrochloride (trientine). QJM-Mon J Assoc Phys 1995, 88(9):609-616.

51. Cho HY, Blum RA, Sunderland T, Cooper GJ, Jusko WJ: Pharmacokinetic and pharmacodynamic modeling of a copper-selective chelator (TETA) in healthy adults. J Clin Pharmacol 2009, 49(8):916-928.

52. Bertrand $M$, Weber $G$, Schoefs B: Metal determination and quantification in biological materials using particle induced X-ray emission. Trends Anal Chem 2003, 22:254-262.

53. Gong D, Lu J, Chen X, Reddy S, Crossman DJ, Glyn-Jones S, Choong YS, Kennedy J, Barry B, Zhang S, et al: A copper(II)-selective chelator ameliorates diabetes-evoked renal fibrosis and albuminuria, and suppresses pathogenic TGF $\beta$ activation in the kidneys of rats used as a model of diabetes. Diabetologia 2008, 51(9):1741-1751.

54. Ward ML, Pope AJ, Loiselle DS, Cannell MB: Reduced contraction strength with increased intracellular $\left[\mathrm{Ca}^{2+}\right]$ in left ventricular trabeculae from failing rat hearts. J Physio/ 2003, 546(Pt 2):537-550.

55. Rousseau E, Smith JS, Meissner G: Ryanodine modifies conductance and gating behavior of single $\mathrm{Ca}^{2+}$ release channel. Am J Physiol 1987, 253(3 Pt 1):C364-C368. 
56. Kim N, Cannell MB, Hunter PJ: Changes in the calcium current among different transmural regions contributes to action potential heterogeneity in rat heart. Prog Biophys Mol Biol 2010, 103(1):28-34.

57. Spurgeon HA, DuBell WH, Stern MD, Sollott SJ, Ziman BD, Silverman HS, Capogrossi MC, Talo A, Lakatta EG: Cytosolic calcium and myofilaments in single rat cardiac myocytes achieve a dynamic equilibrium during twitch relaxation. J Physiol 1992, 447:83-102.

58. Bers DM: Cardiac excitation-contraction coupling. Nature 2002, 415(6868):198-205

59. Okazaki O, Suda N, Hongo K, Konishi M, Kurihara S: Modulation of $\mathrm{Ca}^{2+}$ transients and contractile properties by beta-adrenoceptor stimulation in ferret ventricular muscles. J Physiol 1990, 423:221-240.

60. Akella $A B$, Ding $X L$, Cheng R, Gulati J: Diminished $\mathrm{Ca}^{2+}$ sensitivity of skinned cardiac muscle contractility coincident with troponin T-band shifts in the diabetic rat. Circ Res 1995, 76(4):600-606.

61. Malhotra A, Lopez MC, Nakouzi A: Troponin subunits contribute to altered myosin ATPase activity in diabetic cardiomyopathy. Mol Cell Biochem 1995, 151(2):165-172.

62. Wickley PJ, Shiga T, Murray PA, Damron DS: Propofol decreases myofilament $\mathrm{Ca}^{2+}$ sensitivity via a protein kinase $\mathrm{C}$-, nitric oxide synthase-dependent pathway in diabetic cardiomyocytes. Anesthesiology 2006, 104(5):978-987.

63. Yi T, Cheema Y, Tremble SM, Bell SP, Chen Z, Subramanian M, LeWinter MM VanBuren P, Palmer BM: Zinc-induced cardiomyocyte relaxation in a rat model of hyperglycemia is independent of myosin isoform. Cardiovasc Diabetol 2012, 11:135.

64. Veglio M, Chinaglia A, Cavallo-Perin P: QT interval, cardiovascular risk factors and risk of death in diabetes. J Endocrinol Invest 2004, 27(2):175-181.

65. Wildman RE, Medeiros DM, Hamlin RL, Stills H, Jones DA, Bonagura JD: Aspects of cardiomyopathy in copper-deficient pigs. electrocardiography, echocardiography, and ultrastructural findings. Biol Trace Elem Res 1996, 55(1-2):55-70.

66. Gao WD, Backx PH, Azan-Backx M, Marban E: Myofilament $\mathrm{Ca}^{2+}$ sensitivity in intact versus skinned rat ventricular muscle. Circ Res 1994, 74:408-415.

67. Stephenson DG, Williams DA: Temperature-dependent calcium sensitivity changes in skinned muscle fibres of rat and toad. J Physiol 1985, 360:1-12.

68. Schmidt-Ott SC, Bletz C, Vahl C, Saggau W, Hagl S, Ruegg JC: Inorganic phosphate inhibits contractility and ATPase activity in skinned fibers from human myocardium. Basic Res Cardiol 1990, 85(4):358-366.

69. Hajjar RJ, Schwinger RH, Schmidt U, Kim CS, Lebeche D, Doye AA, Gwathmey JK: Myofilament calcium regulation in human myocardium. Circulation 2000, 101(14):1679-1685.

70. Liu X, Takeda N, Dhalla NS: Troponin I phosphorylation in heart homogenate from diabetic rat. Biochim Biophys Acta 1996, 1316(2):78-84.

71. Malhotra A, Reich D, Reich D, Nakouzi A, Sanghi V, Geenen DL, Buttrick PM: Experimental diabetes is associated with functional activation of protein kinase $C \varepsilon$ and phosphorylation of troponin I in the heart, which are prevented by angiotensin II receptor blockade. Circ Res 1997, 81(6):1027-1033.

72. Glyn-Jones S, Song S, Black MA, Phillips AR, Choong SY, Cooper GJ: Transcriptomic analysis of the cardiac left ventricle in a rodent model of diabetic cardiomyopathy: molecular snapshot of a severe myocardial disease. Physiol Genomics 2007, 28(3):284-293.

73. Jideama NM, Noland TA Jr, Raynor RL, Blobe GC, Fabbro D, Kazanietz MG, Blumberg PM, Hannun YA, Kuo JF: Phosphorylation specificities of protein kinase $C$ isozymes for bovine cardiac troponin I and troponin $T$ and sites within these proteins and regulation of myofilament properties. $J$ Biol Chem 1996, 271(38):23277-23283.

74. da Silva JJ F, Williams RJ: The Biological Chemistry of the Elements: The Inorganic Chemistry of Life. 2nd edition. Oxford, U.K.: Clarendon; 2001:418-435.

75. Lutsenko S, Barnes NL, Bartee MY, Dmitriev OY: Function and regulation of human copper-transporting ATPases. Physiol Rev 2007, 87(3):1011-1046.

76. Gong D, Lu J, Chen X, Choong SY, Zhang S, Chan YK, Glyn-Jones S, Gamble GD, Phillips ARJ, Cooper GJS: Molecular changes evoked by triethylenetetramine treatment in the extracellular matrix of the heart and aorta in diabetic rats. Mol Pharmacol 2006, 70(6):2045-2051.

77. Jüllig M, Hickey AJ, Middleditch MJ, Crossman DJ, Lee SC, Cooper GJS: Characterization of proteomic changes in cardiac mitochondria in streptozotocin diabetic rats using iTRAQ ${ }^{\mathrm{TM}}$ isobaric tags. Proteom Clin Appl 2007, 1:565-576.

78. Bauer SF, Schwarz K, Ruegg JC: Glutathione alters calcium responsiveness of cardiac skinned fibers. Basic Res Cardiol 1989, 84(6):591-596.
79. Kim BE, Turski ML, Nose Y, Casad M, Rockman HA, Thiele DJ: Cardiac copper deficiency activates a systemic signaling mechanism that communicates with the copper acquisition and storage organs. Cell Metab 2010, 11(5):353-363.

80. Williams B: Mechanical influences on vascular smooth muscle cell function. J Hypertens 1998, 16(12 Pt 2):1921-1929.

81. Roberts AB, McCune BK, Sporn MB: TGF $\beta$ : regulation of extracellular matrix. Kidney Int 1992, 41(3):557-559.

82. Aragno M, Mastrocola R, Ghe C, Arnoletti E, Bassino E, Alloatti G, Muccioli G: Obestatin induced recovery of myocardial dysfunction in type 1 diabetic rats: underlying mechanisms. Cardiovasc Diabetol 2012, 11:129.

83. Li CJ, LV L, Li H, Yu DM: Cardiac fibrosis and dysfunction in experimental diabetic cardiomyopathy are ameliorated by alpha-lipoic acid. Cardiovasc Diabetol 2012, 11:73.

doi:10.1186/1475-2840-12-123

Cite this article as: Zhang et al:: Protection of the heart by treatment with a divalent-copper-selective chelator reveals a novel mechanism underlying cardiomyopathy in diabetic rats. Cardiovascular Diabetology 2013 12:123

\section{Submit your next manuscript to BioMed Central and take full advantage of:}

- Convenient online submission

- Thorough peer review

- No space constraints or color figure charges

- Immediate publication on acceptance

- Inclusion in PubMed, CAS, Scopus and Google Scholar

- Research which is freely available for redistribution 